\title{
Deterrence, Lawsuits, and Litigation Outcomes under Court Errors*
}

\author{
Claudia M. Landeo \\ Department of Economics \\ University of Alberta \\ Edmonton, AB T6G 2H4. Canada \\ Maxim Nikitin \\ Department of Economics \\ University of Alberta \\ Edmonton, AB T6G 2H4, Canada \\ and International College \\ of Economics and Finance \\ SU-HSE, Moscow, Russia \\ Scott Baker \\ School of Law \\ University of North Carolina \\ Chapel Hill, NC 27599. USA
}

February 26, 2006

\begin{abstract}
This paper presents a strategic model of liability and litigation under court errors. Our framework allows for endogenous choice of level of care and endogenous likelihood of filing and disputes. We derive sufficient conditions for a unique universally-divine mixed-strategy perfect Bayesian equilibrium under low court errors. In this equilibrium, some defendants choose to be grossly negligent; some cases are filed; and, some lawsuits are dropped, some are resolved out-of-court and some go to trial. We find that court errors in the size of the award, as well as damage caps and split-awards, reduce the likelihood of trial but increase filing and reduce the deterrence effect of punitive damages. We derive conditions under which the adoption of the English rule for allocating legal costs reduces filing.
\end{abstract}

KEYWORDS: Deterrence; Punitive Damage Awards; Bargaining; Asymmetric Information; Court Errors

JEL Categories: K41, C70, D82

\footnotetext{
${ }^{*}$ C.M. Landeo and M. Nikitin acknowledge research support from the University of Alberta (Support for the Advancement of Scholarship Travel Grant; and, Humanities, Fine Arts and Social Sciences Research Conference Travel Grant, 2004-2005). We wish to thank Linda Babcock and Tracy Lewis for their insightful comments and suggestions. We are grateful for comments from conferences participants at the 2005 Annual Meeting of the American Economic Association and the 2004 North American Summer Meeting of the Econometric Society.
} 


\section{Introduction}

Punitive damage awards have been widely criticized for being capricious and "unpredictable". It is hard to predict which actions the jury will find sufficient to justify a punitive award, whether the legal standard is framed in terms of gross negligence, wanton or reckless misconduct or flagrant indifference to the safety of others. ${ }^{1}$ Firms are then unable to take specific measures to avoid liability, and therefore, the deterrence effect of punitive damages ${ }^{2}$ cannot be realized (Economic Report of the President, 2004). ${ }^{3}$ There is also a common perception that excessive punitive damage $\operatorname{awards}^{4}$ generate a plaintiff's windfall (i.e., an amount in excess of the costs of pursuing the punitive claim), which promotes unnecessary litigation (Dodson, 2000) and the escalation of liability insurance premiums. ${ }^{5}$ In an attempt to overcome some of these negative effects, several US states have implemented different kinds of tort reform (Sloane, 1993). Some reforms take the form of caps or limits on punitive damage awards ${ }^{6}$ while others, called "split-awards", have mandated that a share of the award be allocated to the plaintiff with the remainder going to the state. ${ }^{7}$ In addition,

\footnotetext{
${ }^{1}$ The exact words used to describe the standard for punitive damages vary by jurisdiction. In this paper, we use "gross negligence" to represent the punitive damage standard.

${ }^{2}$ Punitive damages are primarily intended to punish defendants for their egregious conduct against society and to deter others from engaging in similar conduct in the future (Sloane, 1993).

${ }^{3}$ Besides undermining deterrence, "unpredictability" of punitive damages may also affect the incentives to file a lawsuit and to litigate.

${ }^{4}$ Justice O'Connor stated that punitive damage awards had "skyrocketed" more than 30 times in the previous ten years, with an increase in the highest award from $\$ 250,000$ to $\$ 10,000,000$ (Browning-Ferris Indus., Inc. v. Kelco Disposal, Inc., 492 U.S. 257, 282, 1989).

${ }^{5}$ Note that liability coverage is widely spread in the United States. In 1990, the total tort liability payments were approximately $\$ 65$ billion (more than $1 \%$ of the U.S. GDP), of which $93.5 \%$ were made by liability insurers (O' Connell, 1994).

${ }^{6}$ Damage caps have been widely implemented in the U.S. Approximately 30 states currently employ some form of liability limits (Babcock and Pogarsky, 1999).

There exist as many different cap schemes as states that employ them. Ranging from Georgia's straightforward cap, which limits punitive damages to $\$ 250,000$, to elaborate attempts to tailor punitive damages to the assets of the defendant and the degree that the defendant benefited from its tortuous conduct. Some states employ a flat dollar cap, a multiplier of compensatory damages, or some combination of both. Some caps pertain to all civil cases, while others apply to certain classes of actions, such as medical malpractice or product liability. "[T]he variety of statutory damage limitations share a common feature-they circumscribe a previously unbounded array of potential trial outcomes" (Babcock and Pogarsky, 1999; p. 345). In this paper, we employ a straightforward cap, one that limits plaintiff's recovery to a specific dollar amount. i.e., reduces the maximum plaintiff's recovery.

${ }^{7}$ Split-awards have been implemented in Alaska, California, Georgia, Illinois, Indiana, Iowa, Missouri, Oregon, and Utah. New Jersey and Texas have contemplated, but not yet adopted, split-award statutes (White, 2002).

Statutes vary with the state: the base for computation of the state's share can be the gross punitive award or the award net of attorney's fees; the state's share can be $50 \%, 60 \%$ or $75 \%$; the destination of the state's funds can be the Treasury, the Department of Human Services or indigent victims funds. For details, see Dodson (2000), Epstein
} 
the adoption of the English rule for allocating legal costs (fee-shifting) ${ }^{8}$ has been proposed. ${ }^{9}$ Proponents of split-awards state that, contrary to damage caps that reduce both the incentives to file a lawsuit and deterrence, split-awards reduce the incentives to file a lawsuit but maintain adequate levels of deterrence and punishment (Sloane, 1993).

This paper attempts to capture the main effects of tort reform of "unpredictable" punitive damages and to assess the effects of "unpredictability" of punitive awards on deterrence and litigation. We present an original game-theoretic framework, which allows for endogenous decision on care, filing and disputes under asymmetric information, heterogeneous types of plaintiffs, and "unpredictable" punitive damages. "Unpredictable" punitive damages are modeled by assuming that ambiguously defined guidelines or jury instructions generate random mistakes from the court in the size of the award. ${ }^{10}$ As a result, "unpredictable" punitive damages are observed. ${ }^{11}$ We then apply this framework to study the effects of court errors, damage caps and split-awards. Finally, we extend our benchmark model to study the effects of fee-shifting.

Our model consists of three stages. In the first stage, the potential injurer decides whether to be grossly negligent. This decision depends on the cost of preventing accidents and on the expected litigation loss in case of an accident. The level of care determines the probability that an accident occurs. If an accident occurs, the second stage, called the filing stage, starts. Nature decides the opportunity cost of time for the potential plaintiff from a continuum of types. ${ }^{12}$ The

(1994), Stevens (1994), Sloane (1993).

${ }^{8}$ Under the American rule each party pays her own litigation costs at trial. In contrast, under the English rule the loser at trial pays the litigation costs of the winner.

${ }^{9}$ Florida temporarily adopted (for the period 1980-1985) a mandatory fee-shifting rule in medical malpractice cases (see Hughes and Snyder, 1995; Snyder and Hughes, 1990).

${ }^{10}$ Alternatively, court errors can be interpreted as errors in the assessment of liability (Polinsky, 1997). Our framework is suitable for both interpretations.

11 "In most states, there is an statute describing the conditions under which punitive damages may be awarded ... These statutes merely provide guidelines for awarding punitive damages. Because the guidelines have not been formulated into exact rules, there is much uncertainty about when punitive damages can be awarded." (Cooter and Ulen, 2004, p. 372). In addition, empirical studies show that cognitive limitations preclude juries to correctly mapping their judgments onto dollar values (Sunstein, Kahneman, and Schkade, 1998).

${ }^{12}$ This cost, independent of the defendant's level of care, captures the effect of personal characteristics of plaintiffs that influence the decision to file a lawsuit. Empirical research on filing has found, that besides the severity and financial losses caused by the injury, demographic and economic characteristics of injured people (age, sex, education, income), which are exogenous to the damage level (and therefore to the level of care that defendants exert), influence the decision of injured people to file a lawsuit. Sabry and Dunbar (2004) find, for instance, that potential plaintiff's income and probability of filing are negatively related. 
potential plaintiff then decides whether to file a lawsuit. ${ }^{13}$ If a lawsuit is filed, the third stage, called the pre-trial bargaining stage, starts. It consists of a signaling-ultimatum game, where two Bayesian risk-neutral parties, an uninformed plaintiff and an informed defendant, ${ }^{14}$ negotiate prior to a costly trial. We derive sufficient conditions for a unique universally-divine (Banks and Sobel, 1987) mixed-strategy perfect Bayesian equilibrium under low court errors. In this equilibrium, some defendants choose to be grossly negligent; some cases are filed; and, some lawsuits are dropped, some are resolved out-of-court and some go to trial. We find that court errors in assessing the size of the award, as well as damage caps and split-awards, reduce the likelihood of trial but increase filing and reduce the deterrence effect of punitive damages. Finally, we derive conditions under which the adoption of the English rule for allocating legal costs reduces filing.

Several policy implications follow from the analysis. First, the model points to the significance of the strategic behavior of plaintiff and defendant for the analysis of the effects of tort reform on deterrence. In particular, the analysis indicates that damage caps and split-awards may reduce the expected loss for a grossly negligent defendant. Therefore both polices can reduce deterrence. Second, the analysis underlines the importance of the defendant's care decision for the study of the effects of tort reform on filing. The analysis indicates, somewhat counter-intuitively, that damage caps and split-awards may increase the number of lawsuits. The reason is this: the reform measures limit the plaintiff's recovery in each individual case but also reduce overall deterrence (i.e., a higher fraction of defendants choose to be grossly negligent). As such, the filing plaintiff has a greater chance of confronting a grossly negligent defendant. This "pool" effect outweighs the plaintiff's lower expected recovery from suit. And, as a result, the tort reform measures generate more lawsuits. ${ }^{15}$

\footnotetext{
Attorney search costs provide another reason why the cost of filing suit might differ across plaintiffs. Some tort victims know attorneys; others do not. If a victim knows an attorney, he might feel more comfortable pursuing a cause of action with that attorney or asking that attorney for a referral. Like other plaintiff-specific characteristics, these search costs are independent of the merits of the case.

${ }^{13}$ Note that the plaintiff's decision to file a lawsuit is influenced by two factors: the opportunity cost of time for the plaintiff, $K_{F}$; and, the plaintiff's expected litigation payoff, which depends on the defendant's level of care.

${ }^{14}$ The defendant possesses information about its level of care and the decision of the court should the case go to trial.

${ }^{15}$ Indeed, this result may reflect "fishing" expeditions by plaintiffs, which are sometimes observed in practice. Given that there are more grossly negligent defendants under damage caps and split-awards, more plaintiffs might
} 
To the best of our knowledge, Hylton (1993) and Hylton (2002) are the only two papers that analyze liability and litigation using game-theoretic models which allow for endogenous decision on care, filing and disputes under asymmetric information and court errors. Hylton (1993) studies the effects of the English rule under certain model parameterization and finds that the likelihood of trials and deterrence (when legal costs are high) are higher under the English rule. Hylton (2002) examines settlement rates, plaintiff win rates and compliance with the due-care standard. He also assesses the effects of the English rule under certain model parameterization and finds that this rule is superior to the American rule in terms of social welfare. The effects of court errors on settlement are ambiguous. The effects of court errors on deterrence and filing, and the effects of damage caps and split-awards are not analyzed.

Png (1987) and Landeo and Nikitin (2005) study tort reform by constructing game-theoretic models, which allow for endogenous decision on care and disputes under asymmetric information. Filing and court errors are not studied. Png (1987) analyzes the effects of damage caps and the adoption of the English rule, and finds that damage caps reduce the expenditures on safety, and fee-shifting lowers the level of care for careful defendants, increases the level of care for negligent defendants, and increases the frequency of trial. The effect of damage caps on disputes is ambiguous and the effect of damage caps on filing is not studied. Landeo and Nikitin (2005) extend previous work on split-awards (Kahan and Tuckman, 1995; Daughety and Reinganum, 2003) ${ }^{16}$ by including

file lawsuits just to see what happens (i.e., whether the defendant caves and makes a positive settlement offer). This result may suggest that states adopting these reforms should, simultaneously, consider strengthening the sanctions for frivolous lawsuits. In addition, this result suggests that plaintiffs' attorneys in states with lower overall deterrence need not do as much investigation of the plaintiff's claim before filing suit. Note also that the same general insight follows in differing regulatory environments. Jurisdictions with looser regulation and, hence, less deterrence of business misconduct, should actually see more lawsuits. This result holds because plaintiffs in these jurisdictions have an incentive to file a lawsuit because they have an increased chance of confronting grossly negligent defendants. Finally, it bears significant mention that this result is similar in spirit to the one derived in Bernardo, Talley and Welch (2000). They show that pro-defendant rules, specifically legal presumptions, can in equilibrium lead to more lawsuits. However, their model doesn't include settlement at the litigation stage. Our framework includes settlement and, as such, can be seen as an extension of their work.

${ }^{16}$ Kahan and Tuckman (1995) construct a simultaneous-move game between a plaintiff and a defendant and find, in the absence of agency problems, that split-awards reduce the plaintiff's litigation expenses and, consequently, reduce the expected amount paid by the defendant. Daughety and Reinganum (2003) incorporate asymmetry of information and strategic behavior to the study of split-awards by modeling the pre-trial bargaining as a game of incomplete information. They find that holding filing constant, split awards simultaneously lower settlement amounts and the likelihood of trial. 
the analysis of deterrence. Their model predicts, under certain conditions that, holding filing constant, a decrease in the plaintiff's share of the award decreases the conditional probability of trial. In addition, they find that split-awards reduce the expenditures on safety.

Snyder and Hughes (1990) and Hughes and Snyder (1995) empirically study the effects of the adoption of the English rule in Florida and find that the English rule increases plaintiff success rates at trial and the average jury awards. These findings suggest that the English rule lowers the filing of low-merit cases. Babcock and Pogarsky (1999) analyze the effect on settlement rates of a damage cap set lower than the value of the underlying claim, using a bargaining experiment. They find that damage caps constrain the parties' judgments and produce more settlement. Landeo, Nikitin, and Babcock (2005) experimentally study split-awards and find that this reform reduces the likelihood of trial.

The paper is organized as follows. Section Two presents the setup of the benchmark model and describes the equilibrium solution. Section Three analyzes the effects of court errors, split-awards, and damage caps under this benchmark model. Section Four describes the effects of fee-shifting. Section Five contains concluding remarks and outlines possible directions for further research.

\section{The Benchmark Model}

We model the interaction between a potential injurer ${ }^{17}$ and a potential plaintiff, as a sequential game of asymmetric information under court errors. In this benchmark model, we assume that the allocation of the legal costs follows the American rule, i.e., each party pays its own legal costs.

We focus our analysis on an equilibrium in which, some defendants choose to be grossly liable; some weak cases are filed; and, some lawsuits are dropped, some are resolved out-of-court and some go to trial. This equilibrium resembles the actual state of affairs of lawsuit termination. ${ }^{18}$

\footnotetext{
${ }^{17}$ We will use the terms injurer and defendant interchangeably.

${ }^{18}$ Data from the U.S. Department of Justice indicate, for a sample of the largest 75 counties (one-year period ending in 1992), that $76.5 \%$ of product liability cases were disposed through agreed settlement and voluntary dismissal and $3.3 \%$ were disposed by trial verdict. The other $20.2 \%$ were disposed as follows: $4.5 \%$ by summary judgment, $0.5 \%$ by default judgment, $6 \%$ were dismissed, $2.7 \%$ by arbitration award, $6.1 \%$ by transfer, and $0.3 \%$ by other dispositions (Smith et al., 1995).
} 


\subsection{Model Setup}

The potential injurer first decides its optimal level of care $e$, i.e., the one that minimizes its total expected loss $L$, where $e \epsilon\left\{e^{0}, e^{1}\right\}$. The injurer is grossly negligent if the level of care chosen is $e^{0}$; otherwise, the injurer is simply negligent and therefore not liable for punitive damages. ${ }^{19}$ High level of care $e^{1}$ costs the injurer $c$, while low level of care $e^{0}$ costs nothing. The probability of accidents is $\lambda(e)$, where $\lambda^{1}=\lambda\left(e^{1}\right)<\lambda\left(e^{0}\right)=\lambda^{0}$.

We define the defendant's total expected loss function as $L=c(e)+\lambda(e) l$, where $l$ is the expected loss from legal action. We take this loss as parametric in order to describe $L$, but ultimately $l$ will be derived as the continuation value of the litigation stage, and hence it will differ for grossly negligent and not liable defendants. The endogenous probability that a defendant is negligent is represented by $p$. The choice of level of care is privately known by the defendant. The potential plaintiff knows that the defendant can choose between these two possible levels, and that only the low level of care implies gross negligence.

If an accident occurs, the filing stage starts. Nature first decides the opportunity cost of time for the potential plaintiff, $K_{F}$. This cost is exogenous and randomly selected from a continuum of types and distributed on $\left[0, \bar{K}_{F}\right] \cdot{ }^{20}$ We define $\phi($.$) and F($.$) as the probability density and cumulative$ density functions of the distribution of plaintiffs by opportunity cost of time, respectively. $\phi($. and $F($.$) , as well as the realization of K_{F}$, are common knowledge. Then, the potential plaintiff decides whether to file a lawsuit. The filing decision is based on the potential plaintiff's costs $K_{F}$ and her beliefs about the level of negligence of the defendant conditional on the occurrence of an accident. With probability $q$ she believes that the defendant is grossly negligent, and with

\footnotetext{
${ }^{19}$ In real-world settings, punitive damages are awarded only in cases where the defendant is found grossly negligent (i.e., where the defendant's actions were malicious, oppressive, gross, willful and wanton, or fraudulent). This implies that a due care standard for gross negligence is applied.

${ }^{20} K_{F}$ is independent of the defendant's level of care. It captures the effect of personal characteristics of potential plaintiffs that influence the decision to file a lawsuit. Empirical research on filing has found, that besides the severity and financial losses caused by the injury, demographic and economic characteristics of injured people (age, sex, education, income), which are exogenous to the damage level (and therefore to the level of care that defendants exert), influence the decision of injured people to file a lawsuit. Sabry and Dunbar (2004) find, for instance, that potential plaintiff's income and probability of filing are negatively related.
} 
probability $(1-q)$ she believes that the defendant is negligent. ${ }^{21}$ A potential plaintiff will file a lawsuit if its expected payoff from suing (i.e., expected litigation payoff minus $K_{F}$ ) is positive. The endogenous probability that a lawsuit is filed is represented by $m$.

If a lawsuit is filed, a pre-trial bargaining negotiation starts. It is modeled as a signalingultimatum game between two Bayesian risk-neutral players, a potential injurer and a potential plaintiff. ${ }^{22}$ The defendant has the first move and makes a settlement proposal. After observing the proposal, the plaintiff, who knows only the two possible choices of care that the defendant can choose, decides whether to drop the case, to accept the defendant's proposal (out-of-court settlement) or to reject the proposal (bring the case to the trial stage). The plaintiff's decision is based on her updated beliefs about the type of defendant she is confronting after observing the defendant's proposal. If the plaintiff drops the case, both players incur no legal costs. If the plaintiff accepts the defendant's proposal, the game ends and the defendant pays the amount proposed to the plaintiff.

If the plaintiff rejects the proposal, plaintiff and defendant incur exogenous legal costs $\left(K_{P}\right.$ and $K_{D}$, respectively) and the court decides whether to award punitive damages $A$ to the plaintiff. "Unpredictable" punitive damages are modeled by assuming that ambiguously defined guidelines for determining the size of punitive damage awards generate random mistakes from the court in the size of the award. We assume that the distribution of the potential awards is binomial with two possible values, 0 and $A$, and that the court awards $A$ with probability $1-\tau_{1}$ and 0 with probability $\tau_{1}$ if the defendant is grossly negligent. If the defendant is negligent, the court then awards $A$ with probability $\tau_{2}$ and 0 with probability $1-\tau_{2}$. We also assume that $\tau_{1}+\tau_{2}<1$. This implies that $\left(1-\tau_{1}\right) A>\tau_{2} A$, i.e., the mean award is higher for the grossly negligent defendant. Therefore, the expected award depends on the defendant's conduct. Under the split-award regime, and in the event that punitive damages $A$ are awarded, the plaintiff receives only a fraction $f$ of the award

\footnotetext{
${ }^{21}$ The values for $q$ and $(1-q)$ are taken as parametric during the pre-trial bargaining subgame, but they ultimately depend on the optimal decision of filing by the plaintiff and on the optimal levels of care chosen by the injurer in the first stage of the game, according to the cost of care and his expected litigation costs (that correspond to the equilibrium in the pre-trial litigation stage).

${ }^{22}$ We model the pre-trial bargaining stage by following Png (1987) and Landeo and Nikitin (2005).
} 
$A$ and the state gets a share $(1-f)$ of the award. We employ here a straightforward definition of cap, one that limits the plaintiff's recovery to a specific dollar amount, and therefore, reduces the maximum plaintiff's recovery $A .{ }^{23}$

The sequence of events in the game is shown in Figure 1.

\section{[INSERT FIGURE 1]}

Note that, $A$ is determined by the jury and the information about the split-award statute is supposed to be kept from the jury, $A$ does not depend on $f$. Then, we will treat $A$ and $f$ as exogenous parameters of the model. Note also that, without loss of generality, for the sake of mathematical tractability and given that our primary goal is to explore the effect of tort reform on punitive damages (i.e., damage caps and split-award statute), we abstract from compensatory damages. ${ }^{24}$ In addition, given that punitive damages are awarded only in cases where the defendant is found grossly negligent (i.e., where the defendant's actions were malicious, oppressive, gross, or willful and wanton), we consider only two choices of care: exert a level of care $e=1$, i.e., meet the standard for gross negligence; and, exert a level of care $e=0$, i.e., not to meet the standard and therefore, be liable for punitive damages. ${ }^{25}$

\footnotetext{
${ }^{23}$ Given that we consider only one positive award $A$, we are implicitly assuming that all plaintiffs have the same damage type. However, court's errors in assessing the size of the award, generates different expected awards for plaintiffs with the same level of damage.

${ }^{24}$ Punitive damage claims are derivative and must be related to a regular tort claim.

Our model can be modified to incorporate compensatory damages, without altering the qualitative predictions presented here, in the following way. Assume that the court awards compensatory damages $C D A$ (common-knowledge) whenever the accident happens (i.e., strict liability applies), but it awards punitive damages $A$ only if the firm fails to achieve the due care standard for gross negligence. Assume also bifurcation of trial, i.e. two separate trials decide on compensatory and punitive damage awards; that the compensatory damages game has the same structure as the punitive damages game presented here; and that legal costs, $K_{P C D A}$ and $K_{D C D A}$ are paid by the plaintiff and defendant, respectively, only in case of trial. Then, in case of an accident, the plaintiff and the defendant do not have asymmetric information with regard to prospective compensatory damage awards, and therefore, they settle out of court. Thus, every defendant will offer $C D A-K_{P C D A}$, and every plaintiff will accept.

Thus, the total loss function is given by $L=c(e)+\lambda(e)\left(C D A-K_{P C D A}+l\right)$, where $l$ is the expected loss from legal action related to punitive damages. It is easy to show that all qualitative results presented in Sections 4 and 5 will hold.

${ }^{25}$ Note that our qualitative results hold in a framework that allows for three choices of care: careful, negligent and grossly negligent. Assume that the costs of care are strictly increasing in the amount of care and that punitive damages are awarded only in case of gross negligence. Then, if the cost of being careful is sufficiently high, the strategy "careful" is strictly dominated by the strategy "negligent". So, the rational defendant will randomize only between negligence and gross negligence. The influence of the choice of care on the litigation stage will be then through $\hat{q}$ and $(1-\hat{q})$, where $\hat{q}$ represents the probability that an accident is caused by a grossly negligent defendant. Hence, all our qualitative results will hold.
} 


\subsection{Equilibrium under Low Court Errors}

We focus our analysis on the equilibrium under low court errors, i.e., $\tau_{1}$ and $\tau_{2}$ are below some threshold, and $\tau_{1}+\tau_{2}<1$. This characteristic of court errors conforms to the empirical findings. ${ }^{26}$ In this equilibrium, some defendants will choose to be grossly negligent, while others will choose to be negligent; and only some cases are filed. In addition, some negligent defendants reveal their gross negligence through offers to settle, which are accepted by plaintiffs. Other gross negligent defendants try to hide their type by mimicking the behavior of negligent defendants and make no offer. There is a sufficient number of those grossly negligent and "dishonest" defendants for the information provided to the plaintiff by the action chosen by the defendant (refusal to settle) to be not transparent. Therefore, some plaintiffs respond to a refusal to settle by bringing their case to trial, while others drop their action.

This equilibrium constitutes the unique perfect Bayesian equilibrium of the game that survives Banks and Sobel's (1987) universal divinity refinement ${ }^{27}$ under the following conditions:

$$
\begin{gathered}
\left(1-\tau_{1}\right) f A-K_{P}>\tau_{2} A+K_{D}, \\
0 \leq \tau_{1}<\min \left\{\overline{\tau_{1}}, 1-\frac{F^{-1}(m)+K_{P}}{f A}\right\}, \\
0 \leq \tau_{2}<\min \left\{\overline{\tau_{2}}\left(\tau_{1}\right), \frac{K_{P}}{f A}\right\},
\end{gathered}
$$

where $m=\frac{c}{\left.\left[\left(1-\tau_{1}\right) f A-K_{P}\right)\right]\left[\lambda^{0}-\lambda^{1} \frac{\left(\tau_{2} A+K_{D}\right)}{\left(1-\tau_{1}\right) A+K_{D}}\right]} \cdot \overline{\tau_{1}}$ and $\overline{\tau_{2}}\left(\tau_{1}\right)$ correspond to the values for $\tau_{1}$ and $\tau_{2}$ for which $m=1$ (see Proof of Proposition 1 in Appendix A).

Condition (1) rules out the pooling perfect Bayesian equilibrium where negligent defendants behave as grossly negligent defendants in the pre-trial bargaining stage. It also guarantees that at least some potential plaintiffs file a lawsuit (i.e., it ensures $m>0$ ). ${ }^{28}$ Conditions (2) and (3) guarantee that some but not all defendants choose to be grossly negligent (i.e., they ensure $q<1$ and $q>0$, respectively). Additionally, conditions (2) and (3) ensure that not all potential plaintiffs

\footnotetext{
${ }^{26}$ Tullock (1980) estimates the probability of legal error generally to be about 0.13 .

${ }^{27}$ See Reinganum and Wilde (1986), Schweizer (1989), and Landeo and Nikitin (2005) for previous applications of the universal divinity refinement to litigation games.

${ }^{28}$ In addition, it ensures that $\tau_{1}+\tau_{2}<1$.
} 
file a lawsuit (i.e., they ensure $m<1$ ). Then, conditions $(2)$ and $(3)$ rule out the pooling perfect Bayesian equilibrium where the deterrence effect of punitive awards totally vanishes. In this pooling equilibrium, no defendant chooses to be negligent, all injured plaintiffs file a lawsuit and all cases are settled out-of-court. ${ }^{29}$

Under conditions (1)-(3), however, the pre-trial bargaining subgame has other partially separating equilibria ${ }^{30}$ and other pooling equilibria, but they do not survive the universal divinity refinement (see Appendix A for details).

Proposition 1 characterizes the unique universally divine equilibrium of the game.

Proposition 1. Assume that conditions (1)-(3) hold. Then, the following strategy profile, together with the players' beliefs, represents the equilibrium path of the unique universally divine Perfect Bayesian equilibrium of the game.

\section{Strategy Profile}

1) The plaintiff files a lawsuit with probability $m=\frac{c}{\left.\left[\left(1-\tau_{1}\right) f A-K_{P}\right)\right]\left[\lambda^{0}-\lambda^{1} \frac{\left(\tau_{2} A+K_{D}\right)}{\left(1-\tau_{1}\right) A+K_{D}}\right]}$. In response to an offer $S_{1}=0$, the plaintiff rejects the offer (goes to trial) with probability $\alpha=\frac{\left(1-\tau_{1}\right) f A-K_{P}}{\left(1-\tau_{1}\right) A+K_{D}}$ and accepts the offer (drops the action) with probability $(1-\alpha)$; the plaintiff always accepts the offer $S_{2}=\left(1-\tau_{1}\right) f A-K_{P}$ (settles out-of-court).

2) The defendant chooses to be negligent with probability $p=\frac{\left[\frac{\left(1-\tau_{1}\right) f A-F^{-1}(m)-K_{P}}{f A\left(1-\tau_{1}-\tau_{2}\right)}\right] \lambda^{0}}{\left[\frac{\left(1-\tau_{1}\right) f A-F^{-1}(m)-K_{P}}{f A\left(1-\tau_{1}-\tau_{2}\right)}\right] \lambda^{0}+\left[\frac{F^{-1}(m)+K_{P}-\tau_{2} f A}{f A\left(1-\tau_{1}-\tau_{2}\right)}\right] \lambda^{1}}$. The grossly negligent defendant makes no offer (offers $\left.S_{1}=0\right)$ with probability $\beta=\frac{\left(K_{P}-\tau_{2} f A\right)(1-q)}{q\left[\left(1-\tau_{1}\right) f A-K_{P}\right]}$ and offers $S_{2}=\left(1-\tau_{1}\right) f A-K_{P}$ with probability $(1-\beta)$. The negligent defendant always makes no offer (offers $S_{1}=0$ ).

\section{Plaintiff's Beliefs}

The equilibrium beliefs are as follows. If an accident occurs, the plaintiff believes with probability

\footnotetext{
${ }^{29}$ Intuitively, at high levels of court error (i.e., when $\tau_{1} \geq \overline{\tau_{1}}$ or $\tau_{2} \geq \overline{\tau_{2}}$ ), the incentives for filing are maximized, and the highest level of filing is achieved, i.e., $m=1$. At those levels of error, filing is insensitive to the liability of defendants, and therefore, there are not incentives to invest in care.

${ }^{30}$ These other partially separating equilibria do not allow for cases to be dropped, and therefore, they do not conform to the empirical regularities on termination of lawsuits.
} 
$(1-q)$ that she is confronting a negligent defendant, and with probability $q$ that she is confronting a grossly negligent defendant. When the plaintiff receives an offer, she updates her beliefs using Bayes' rule: when she receives an offer $S_{1}=0$, she believes with probability $\frac{(1-q)}{q \beta+(1-q)}$ that she is confronting a negligent defendant and with probability $\frac{q \beta}{q \beta+(1-q)}$ that she is confronting a grossly negligent defendant; when the plaintiff receives an offer $S_{2}=f A-K_{P}$, she believes with certainty that she is confronting a grossly negligent defendant. The off-equilibrium beliefs are as follows. When the plaintiff receives an offer $S^{\prime}$ such that $0<S^{\prime}<\left(1-\tau_{1}\right) f A-K_{P}$ or when she receives an offer $S^{\prime}>\left(1-\tau_{1}\right) f A-K_{P}$, she believes that this offer was made by a grossly negligent defendant.

Proof. See Appendix A.

Although the model is solved formally in Appendix A, here we outline the main steps of the solution. The model is solved backwards. We start by finding the solution of the pre-trial bargaining subgame. ${ }^{31}$ Then, we evaluate the plaintiff's filing decision and assess the defendant's choice of care.

Consider the expected payoffs for the plaintiff, no-grossly-negligent and grossly negligent defendants, in terms of $\alpha$ and $\beta$. The expected payoff for the plaintiff is $V_{P}=(1-q)\left[\alpha\left(\tau_{2} f A-K_{P}\right)+(1-\right.$ $\alpha)(0)]+q\left\{\beta\left[\alpha\left[\left(1-\tau_{1}\right) f A-K_{P}\right]+(1-\alpha)(0)\right]+(1-\beta)\left[\left(1-\tau_{1}\right) f A-K_{P}\right]\right\} ;$ the expected payoff for the negligent defendant is $V_{D^{1}}=\alpha\left(-\tau_{2} A-K_{D}\right)+(1-\alpha)(0)$; and, the expected payoff for the grossly negligent defendant is $V_{D^{0}}=\beta\left[\alpha\left(-\left(\left(1-\tau_{1}\right) A+K_{D}\right)\right)+(1-\alpha)(0)\right]+(1-\beta)\left[-\left(\left(1-\tau_{1}\right) f A-K_{P}\right)\right]$.

The values of $\alpha$ and $\beta$ are calculated from the condition that both parties (the plaintiff and the grossly negligent defendant) have to be indifferent between their strategies to mix them. So,

$$
\left(1-\tau_{1}\right) f A-K_{P}=\alpha\left[\left(1-\tau_{1}\right) A+K_{D}\right]+(1-\alpha)(0),
$$

and

$$
0=\frac{q \beta}{q \beta+(1-q)}\left[\left(1-\tau_{1}\right) f A-K_{P}\right]+\frac{1-q}{q \beta+(1-q)}\left(\tau_{2} f A-K_{P}\right) .
$$

\footnotetext{
${ }^{31}$ The values for $q$ and $(1-q)$ are taken as parametric during the pre-trial bargaining subgame, but they ultimately depend on the optimal filing decision by the plaintiff and on optimal levels of care chosen by the injurer in the first stage of the game, according to the cost of care and his expected litigation costs (that correspond to the equilibrium in the pre-trial litigation stage).
} 
Equation (4) says that a grossly negligent defendant is indifferent between admitting his gross negligence (i.e., offering $\left.S_{2}=\left(1-\tau_{1}\right) f A-K_{P}\right)$ and stating that he is negligent (i.e., offering $\left.S_{1}=0\right)$ with the risk to lose $\left(1-\tau_{1}\right) A+K_{D}$ if the case goes to court. Equation (5) says that a plaintiff is indifferent between dropping the case and getting a payoff of $S_{1}=0$ and going to court. Solving (4) for $\alpha$ and (5) for $\beta$, we get

$$
\alpha=\frac{\left(1-\tau_{1}\right) f A-K_{P}}{\left(1-\tau_{1}\right) A+K_{D}}
$$

and

$$
\beta=\frac{\left(K_{P}-\tau_{2} f A\right)(1-q)}{q\left[\left(1-\tau_{1}\right) f A-K_{P}\right]} .
$$

The expected litigation payoffs for the plaintiff, negligent and grossly negligent defendant are $V_{P}=\left[q\left(1-\tau_{1}\right)+(1-q) \tau_{2}\right] f A-K_{P}, V_{D^{1}}=-\left[\frac{\left(1-\tau_{1}\right) f A-K_{P}}{\left(1-\tau_{1}\right) A+K_{D}}\right]\left(\tau_{2} A+K_{D}\right)$ and $V_{D^{0}}=-\left[\left(1-\tau_{1}\right) f A-\right.$ $\left.K_{P}\right]$, respectively.

The conditional probability of trial is

$$
\alpha[1-q(1-\beta)]=\frac{f A(1-q)\left(1-\tau_{1}-\tau_{2}\right)}{\left(1-\tau_{1}\right) A+K_{D}} .
$$

The conditional probability of out-of-court settlement is

$$
q(1-\beta)=q\left\{1-\frac{\left(K_{P}-\tau_{2} f A\right)(1-q)}{q\left[\left(1-\tau_{1}\right) f A-K_{P}\right]}\right\} .
$$

And, the conditional probability of dropping a case is

$$
(1-\alpha)[1-q(1-\beta)]=\left[1-\frac{\left(1-\tau_{1}\right) f A-K_{P}}{\left(1-\tau_{1}\right) A+K_{D}}\right]\left\{1-q\left[1-\frac{\left(K_{P}-\tau_{2} f A\right)(1-q)}{q\left[\left(1-\tau_{1}\right) f A-K_{P}\right]}\right]\right\}
$$

Using the previous results on plaintiff's expected payoff from litigation, we analyze now the plaintiff's decision about filing.

A plaintiff will file a lawsuit if her expected payoff from suing (i.e., expected litigation payoff net of $K_{F}$ ) is positive, ${ }^{32}$ that is if

$$
\left[q\left(1-\tau_{1}\right)+(1-q) \tau_{2}\right] f A-K_{P}-K_{F}>0 .
$$

\footnotetext{
${ }^{32}$ Note that the plaintiff's decision to file a lawsuit is influenced by two factors: the opportunity cost of time for the plaintiff, $K_{F}$; and, the plaintiff's expected litigation payoff, which depends on the defendant's level of care.
} 
Then, the probability of filing is

$$
F\left(q\left(1-\tau_{1}\right) f A+(1-q) \tau_{2} f A-K_{P}\right) \equiv m
$$

Now, we will proceed to analyze the defendant's choice of care. The defendant decides the level of care $y$ taking into account $L^{i}=c\left(y^{i}\right)+m \lambda^{i} l^{i}(i=0,1)$, where $l^{i}$ is the expected loss from legal action, different for no-grossly-negligent and grossly negligent defendants.

$$
\begin{cases}c+m \lambda^{1} l^{1} & \text { if } e^{1} \\ 0+m \lambda^{0} l^{0} & \text { if } \quad e^{0}\end{cases}
$$

where $c$ is the cost of care (i.e., cost of choosing to be negligent); $m$ is the probability that a lawsuit is filed; $\lambda^{i}$ is the probability of an accident; $l^{0}=\left[\left(1-\tau_{1}\right) f A-K_{P}\right]$ is the expected litigation loss for a grossly negligent defendant, $l^{1}=\left[\left(\frac{\left(1-\tau_{1}\right) f A-K_{P}}{\left(1-\tau_{1}\right) A+K_{D}}\right]\left(\tau_{2} A+K_{D}\right)\right.$ is the expected litigation loss for a negligent defendant.

We construct an equilibrium in which some defendants choose to be negligent and others choose to be grossly negligent. This is the equilibrium behavior that conforms to the asymmetry of the pre-trial bargaining subgame and to the real-world behavior of potential injurers.

The defendant will randomize only if he is indifferent between the expected payoffs from both strategies.

$$
c+m \lambda^{1}\left[\frac{\left(1-\tau_{1}\right) f A-K_{P}}{\left(1-\tau_{1}\right) A+K_{D}}\right]\left(\tau_{2} A+K_{D}\right)=m \lambda^{0}\left[\left(1-\tau_{1}\right) f A-K_{P}\right]
$$

This condition can be rewritten as

$$
c=m\left[\left(1-\tau_{1}\right) f A-K_{P}\right]\left[\lambda^{0}-\lambda^{1} \frac{\left(\tau_{2} A+K_{D}\right)}{\left.\left(1-\tau_{1}\right) A+K_{D}\right)}\right],
$$

where the left-hand side of equation (15) represents the defendant's cost of accident prevention and the right-hand side represents the defendant's benefit from accident prevention, i.e., difference in the unconditional expected litigation costs for grossly negligent and negligent defendants.

From equation (14), the indifference condition for randomization between $e^{1}$ and $e^{0}$, we find $m$, the probability of filing that supports the randomization of choice of care.

$$
m=\frac{c}{\left.\left[\left(1-\tau_{1}\right) f A-K_{P}\right)\right]\left[\lambda^{0}-\lambda^{1} \frac{\left(\tau_{2} A+K_{D}\right)}{\left(1-\tau_{1}\right) A+K_{D}}\right]} .
$$


It is important to note, that $m>0$ because $\lambda^{0}>\lambda^{1}$ (by assumption) and because condition (2) ensures that $\frac{\tau_{2} A+K_{D}}{\left(1-\tau_{1}\right) A+K_{D}}<1$. In addition, conditions (3) and (4) guarantee that $m<1$ (see Proof of Proposition 1 in Appendix A).

Now we can obtain $q$, the probability that an accident is caused by a grossly negligent defendant. From equation (12),

$$
q\left(1-\tau_{1}\right) f A+(1-q) \tau_{2} f A-K_{P}=F^{-1}(m)
$$

Then,

$$
q=\frac{F^{-1}(m)+K_{P}-\tau_{2} f A}{f A\left(1-\tau_{1}-\tau_{2}\right)}
$$

The expression for $q$ is always positive, because $K_{P}>\tau_{2} f A$ by condition (3). In addition, condition (2) implies that $q<1$ (see Proof of Proposition 1 in Appendix A).

Finally, we get the expression for $p$, the probability that a defendant chooses to be negligent. By Bayes' rule, $q=\frac{\lambda^{0}(1-p)}{\lambda^{0}(1-p)+\lambda^{1} p}$. Solving for $p$, we get

$$
p=\frac{\lambda^{0}(1-q)}{\lambda^{0}(1-q)+\lambda^{1} q} .
$$

Using equation (18),

$$
p=\frac{\left[\frac{\left(1-\tau_{1}\right) f A-F^{-1}(m)-K_{P}}{f A\left(1-\tau_{1}-\tau_{2}\right)}\right] \lambda^{0}}{\left[\frac{\left(1-\tau_{1}\right) f A-F^{-1}(m)-K_{P}}{f A\left(1-\tau_{1}-\tau_{2}\right)}\right] \lambda^{0}+\left[\frac{F^{-1}(m)+K_{P}-\tau_{2} f A}{f A\left(1-\tau_{1}-\tau_{2}\right)}\right] \lambda^{1}} .
$$

Given the previous results, the probability of accident is $\mu=\lambda^{1} p+\lambda^{0}(1-p)$, where $p$ is given by equation (20). Now, we can derive the unconditional probability trial. The probability of trial conditional on occurrence of the accident and filing is $\frac{f A(1-q)\left(1-\tau_{1}-\tau_{2}\right)}{\left(1-\tau_{1}\right) A+K_{D}}$, then the unconditional probability of trial is $\frac{f A(1-q)\left(1-\tau_{1}-\tau_{2}\right)}{\left(1-\tau_{1}\right) A+K_{D}} m \mu$. Given that $(1-q)=\frac{\lambda^{1} p}{\lambda^{0}(1-p)+\lambda^{1} p}$ is the probability that a defendant has been negligent conditional on the occurrence of an accident, then, the unconditional probability of trial is equal to $\frac{f A \lambda^{1} p\left(1-\tau_{1}-\tau_{2}\right)}{\left(1-\tau_{1}\right) A+K_{D}} m$, where $m$ is given by equation (16) and $p$ is given by equation (20). Similarly, given that the probability of out-of-court settlement conditional on occurrence of the accident and filing is equal to $q\left[1-\frac{\left(K_{P}-\tau_{2} f A\right)(1-q)}{q\left[\left(1-\tau_{1}\right) f A-K_{P}\right]}\right]$, then the unconditional probability of out-of-court settlement is equal to $\mu-\frac{\lambda^{1} p\left[f A\left(1-\tau_{1}\right)-\tau_{2}\right]}{\left(1-\tau_{1}\right) f A-K_{P}} m$. Finally, given 
that the probability of dropping a case conditional on the occurrence of an accident and filing is $\left[1-\frac{\left(1-\tau_{1}\right) f A-K_{P}}{\left(1-\tau_{1}\right) A+K_{D}}\right]\left\{1-q\left[1-\frac{\left(K_{P}-\tau_{2} f A\right)(1-q)}{q\left[\left(1-\tau_{1}\right) f A-K_{P}\right]}\right]\right\}$, then the unconditional probability of dropping a case is equal to $\left.\lambda^{1} p\left[\frac{\left(1-\tau_{1}\right)(1-f) A+K_{P}+K_{D}}{\left(1-\tau_{1}\right) A+K_{D}}\right]\left[\frac{\left(1-\tau_{1}\right) f A-\tau_{2} f A}{\left(1-\tau_{1}\right) f A-K_{P}}\right)\right] m \cdot 33$

\section{Comparative Statics under the Benchmark Model}

This section analyzes the effects of court errors, damage caps and split-awards, on the likelihood of trials (conditional probability of trial) and filing $(m)$, on the deterrence effect of punitive awards $(p)$, and on the probability of an accident $(\mu)$. We assume that the changes in $\tau_{1}, \tau_{2}, A$, or $f$ are small enough to preserve conditions (1)-(3).

\section{$3.1 \quad$ Effects of Court Errors}

Punitive awards have been widely criticized for their "unpredictability". It has been argued that this "unpredictability" lowers the deterrence effect of punitive damages (see for example, Polinsky and Shavell, 1989). We show here that randomness in the size of the award, i.e., court errors, indeed lower deterrence. In addition, court errors increase filing but reduce the likelihood of trials.

Proposition 2. A reduction in the size of the expected award for a plaintiff confronting a grossly negligent defendant (i.e., an increase in the probability that a grossly negligent defendant will not be asked to pay any award, $\tau_{1}$ ) decreases the probability of trial, increases the probability of filing, decreases the deterrence effect of punitive awards and therefore, increases the probability of an accident.

Proof. See Appendix A.

\footnotetext{
${ }^{33}$ Note that the signaling framework adopted here involves no trial for grossly negligent types who reveal, and positive probability for grossly negligent types who pool with no-grossly-negligent types. On the other hand, a separating equilibrium in a screening framework (with the same information structure) would involve a plaintiff's demand which is accepted by grossly negligent defendants and rejected by negligent defendants. Hence, there are some qualitative differences in the equilibria of the signaling and screening models. However the comparative statics results are qualitatively similar across models, with the exception that, given that $m$ does not depend on $f$ in the screening model, there is no impact of split-awards on the probability of filing under that framework. Hence, the effects of split-awards on filing can be analyzed only under a signaling framework. This is reason for which we decided to adopt this framework.
} 
An increase in $\tau_{1}$ reduces the plaintiff's expected payoff from suing (expected litigation payoff net of filing cost) by lowering the expected recovery at trial. But, an increase in $\tau_{1}$ also increases the plaintiff's expected payoff from suing by reducing deterrence and therefore, increasing the probability that an accident is caused by a grossly negligent defendant $q$. This effect operates as follows. An increase in $\tau_{1}$ reduces the expected litigation losses for a grossly negligent defendant, and therefore, reduces the difference in expected litigation losses for negligent and grossly negligent defendants (i.e., potential injurer's benefit from taking care). Then, deterrence is reduced (and probability of accidents is increased), and therefore, the probability that an accident is caused by a grossly negligent defendant, $q$, increases. We show that the increase in the plaintiff expected payoff from suing (due to an increase in $q$ ) offsets the reduction due to a lower expected recovery at trial. Hence, the probability of filing increases. ${ }^{34}$

In addition, given that an increase in $\tau_{1}$ reduces the likelihood that a grossly negligent defendant will pay $A$, plaintiffs are less willing to go to court and therefore, plaintiffs accept more frequently out-of-court offers, i.e., the probability of rejection of a zero-offer by the plaintiff, $\alpha$, goes down. ${ }^{35}$ Hence, the probability of trial decreases.

Proposition 3. An increase in the size of the expected award for a plaintiff confronting a negligent defendant (i.e., an increase in the probability that a negligent defendant will be asked to pay $A$, $\left.\tau_{2}\right)$ increases the probability of filing.

Proof. See Appendix A.

An increase in $\tau_{2}$, i.e., an increase in the likelihood that a negligent defendant will be asked to pay $A$, increases the plaintiff's expected payoff from suing. Thus, the incentives to file a lawsuit

\footnotetext{
${ }^{34}$ Note that the increase in filing increases the incentives to take care. However, the effect of $\tau_{1}$ on the difference in expected litigation losses for negligent and grossly negligent defendants offsets this second effect. As a consequence, an increase in $\tau_{1}$ reduces deterrence.

${ }^{35}$ Note also that an increase in $\tau_{1}$ reduces the expected loss at trial for a grossly negligent defendant $\left(1-\tau_{1}\right) A+K_{D}$, and therefore, reduces the willingness of grossly negligent defendants to make positive out-of-court offers (i.e., increases the likelihood that a zero offer comes from a grossly negligent defendant). This will decrease the plaintiff's willingness to accept zero offers (i.e., increases $\alpha$ ). However, we show that this latter effect is offset by the first effect of $\tau_{1}$ (reduction in $\alpha$ ).
} 
are higher and the probability of filing increases. ${ }^{36}$

\subsection{Effects of Damage Caps and Split-Awards}

We assess the effects of the adoption of damage caps and split-awards. Given that damage caps reduce the maximum plaintiff's recovery at trial $A$, the adoption of damage caps is represented by a reduction in $A$. The introduction of split-awards is represented by a reduction in $f$, the plaintiff's share of the punitive award.

Proponents of split-awards argue that, in contrast to caps that reduce both the plaintiff's windfall and the deterrence effect of the punitive awards, the split-award statute constitutes a "move toward effectuating the true purpose of punitive damages" (Sloane, 1993, p. 473). ${ }^{37}$ They claim that split-awards reduce the plaintiff's windfall but maintain adequate levels of deterrence and punishment. ${ }^{38}$ These claims are based on the observation that both, split-awards and damage caps reduce the plaintiff's recovery at trial, but contrary to damage caps, split-awards do not reduce the loss for the grossly negligent defendant at trial. We show here, that the decision on care depends not only on the loss for the defendant at trial but also on the out-of-court settlement outcomes (which are affected by both reforms). Given that the incentives to take care are lower under both reforms, both split-awards and damage caps reduce the deterrence effect of punitive damages. We also show that, if we consider the impact of these reforms not only on the plaintiff's recovery at trial but also on deterrence, then we can conclude that both, split-awards and caps increase the likelihood of filing.

In addition, we find that the adoption of split-awards and damage caps reduce the likelihood of trials. Experimental studies conducted by Babcock and Pogarsky (1999), and Landeo, Nikitin, and Babcock (2005), on damage caps and split-awards, respectively, support our theoretical results.

\footnotetext{
${ }^{36}$ The effects of $\tau_{2}$ on the deterrence effect of punitive awards, and on the probabilities of an accident and disputes are ambiguous.

${ }^{37}$ The main purposes behind the award of punitive damages are to punish defendants for their egregious conduct against society and to deter others from engaging in similar conduct in the future. In addition, punitive damages serve to encourage plaintiffs to bring forth minor criminal offenses that are not likely to be prosecuted yet nonetheless are offensive to society, and compensate plaintiffs for their attorneys' fees (Sloane, 1993).

${ }^{38}$ In addition, split-awards allow the plaintiffs to receive a share of the awards for payment of attorney fees and rewards for their civil duty as "private attorney generals" (Case Note, 1993; Dodson, 2000; Evans, 1998; Epstein, 1994; Stevens, 1994; Sloane, 1993).
} 
Proposition 4. The introduction of damage caps or split-awards decrease the probability of trial, increases the probability of filing, decreases the deterrence effect of punitive awards and therefore, increases the probability of an accident.

Proof. See Appendix A.

A decrease in $A$ or $f$ reduces the plaintiff's expected payoff from suing (i.e., reduces the incentives to file a lawsuit) by lowering the expected recovery at trial. But a reduction in $A$ or $f$ also increases the plaintiff's expected payoff from suing by lowering deterrence and therefore, increasing the likelihood of confronting a negligent defendant, $q$. This effect operates in the following way. A decrease in $A$ or $f$ reduces the defendant's benefit from accident prevention (i.e., difference in the expected litigation costs for grossly negligent and negligent defendants), and therefore, reduces the incentives to take care. ${ }^{39}$ As a consequence, the deterrence effect of punitive damages is reduced (and the probability of accidents increases). Then, it will be more likely that accidents be caused by negligent defendants, i.e., $q$ will be higher. Hence, the plaintiff's expected payoff from suing will increase. We show that the increase in the plaintiff's expected payoff from suing (due to an increase in $q$ ) offsets the reduction due to a lower expected recovery at trial. As a result, the probability of filing increases. ${ }^{40}$

In addition, given that a decrease in $A$ or $f$ reduces the expected recovery at trial, plaintiffs are more willing to accept a zero offer. Then, the probability that the plaintiff rejects a zero offer, $\alpha$, goes down. As a consequence, the probability of trial decreases. ${ }^{41}$

\footnotetext{
${ }^{39}$ Specifically, a decrease in $A$ or $f$ reduces the defendant's benefit from accident prevention through its effect on the probability that a plaintiff rejects a zero offer: a reduction in $f$ or $A$ lowers the plaintiff's expected recovery at trial, and therefore, reduces the probability that a plaintiff rejects a zero offer. As a consequence, the expected loss for a grossly negligent defendant is reduced, the incentives to take care are also reduced, and $q$ increases.

In case of damage caps, however, there is an additional effect to consider. A reduction in $A$ also decreases the difference in the expected losses at trial for grossly negligent and negligent defendants, and therefore, reduces the incentives to take care and increases $q$ even more. Hence, damage caps and split-awards increase the probability that a grossly negligent defendant is involved in an accident, $q$, but there are some quantitative differences in the effects of both reforms.

${ }^{40}$ Note that the increase in filing increases the incentives to take care. However, the effect of $A$ or $f$ on the difference in expected litigation losses for grossly negligent and negligent defendants offsets this second effect. As a consequence, a decrease in $A$ or $f$ reduces deterrence.

${ }^{41}$ Note that in case of damage caps, there is an additional effect to consider. A reduction in $A$ also decreases the expected loss at trial for a grossly negligent defendant, and therefore, reduces the willingness of negligent defendants
} 


\section{Effects of Fee-Shifting}

We now proceed to analyze the effects of adopting the English rule for allocating legal costs by comparing the results from the benchmark model with the results from a modified version of this model under the English rule. ${ }^{42}$

Empirical studies of the effects of the adoption of the English rule in Florida during the period 1980-1985 (Hughes and Snyder, 1995; Snyder and Hughes, 1990) indicate that fee-shifting results in higher compensations and higher frequency of cases where plaintiffs win. These findings suggest a reduction of filing of less meritorious cases. Our model indeed captures this effect. Proposition 5 summarizes this result.

Proposition 5. The adoption of the English rule as a method for allocating legal costs decreases filing if $\tau_{1}<\frac{K_{P}}{K_{P}+K_{D}}$.

Proof. See Appendix A.

The condition $\tau_{1}<\frac{K_{P}}{K_{P}+K_{D}}$ implies that $\tau_{1}$ should be relatively small. This condition conforms to empirical findings (Tullock, 1980). Note also that this is a sufficient, but not necessary condition.

Intuitively, given that under the English rule the plaintiff should pay the legal costs of both parties in case of losing at trial, the plaintiffs expected payoff from suing is lower under the English rule. Then, the incentives to file a lawsuit are reduced and hence, the likelihood of filing is lower under the English rule.

If, in addition, $\tau_{2}$ is sufficiently big, the English rule raises the likelihood of trials but also increases the deterrence effect of punitive damages and therefore, lowers the probability of an

to make positive out-of-court offers (i.e., increases the likelihood that a zero offer comes from a negligent defendant). This will decrease the plaintiff's willingness to accept zero offers (i.e., increases $\alpha$ ). We show that this latter effect is offset by the first effect of $A$ (reduction in $\alpha$ ). Hence, damage caps and split-awards reduce the probability of trial. Note however, that there are some quantitative differences in the effects of both reforms.

${ }^{42}$ The setup of this modified model is similar to the one presented in Section 2. The only difference is the rule for allocating legal costs in case of trial: under the English rule, the losing party at trial pays the legal costs of both parties. The structure of the equilibrium is also similar to the one adopted for the benchmark model. See Appendix A for details about the equilibrium strategy profile and beliefs of the model under the English rule.

We assume that conditions stated in Proposition 1 and Proposition A1 (equilibrium under the English Rule model, in Appendix A) hold. 
accident. Proposition 6 summarizes this result.

Proposition 6. The adoption of the English rule as a method for allocating legal costs increases the probability of trial, increases the deterrence effect of punitive awards and therefore, decreases the probability of an accident if $\tau_{1}<\frac{K_{P}}{K_{P}+K_{D}}$ and $\tau_{2}>\frac{K_{D}}{K_{P}+K_{D}}$.

Proof. See Appendix A.

Note that the conditions $\tau_{1}<\frac{K_{P}}{K_{P}+K_{D}}$ and $\tau_{2}>\frac{K_{D}}{K_{P}+K_{D}}$ are sufficient but not necessary conditions.

The difference in expected litigation losses for grossly negligent and no-grossly-negligent defendants is higher under the English rule. Then, the incentives to take care may be greater and the deterrence effect may be higher under the English rule, even though the likelihood of filing is lower.

This higher deterrence under the English rule reduces the likelihood of confronting negligent defendants at trial and therefore, decreases the willingness of plaintiffs to go to trial (i.e., the probability of rejecting zero offers goes down). This effect decreases the likelihood of trials. However, the higher deterrence also increases the willingness of defendants to make no offers (i.e., the probability of making zero offers goes up). This effect increases the likelihood of trials. We show that, if $\tau_{2}$ is big enough and $\tau_{1}$ is small enough, the second effect offsets the first one, and therefore, the likelihood of trials is higher under the English rule. ${ }^{43}$

\section{Conclusions}

This paper presents a strategic model of liability and litigation under court errors. The framework allows for endogenous decision about investment in accident prevention, and endogenous likelihood of filing and disputes. This article is not the first to consider liability and litigation in the same framework but is the first to apply a framework with endogenous decisions on care, filing and dispute, under court errors, to the analysis of damage caps and split-awards.

\footnotetext{
${ }^{43}$ From the empirical findings (Tullock, 1980), we should infer that court errors are in general low. Then, even though $\tau_{2}$ does not meet the sufficient condition on Proposition 6 , we should expect that the results stated in that proposition be more likely as $\tau_{2}$ increases.
} 
We construct an equilibrium under low court errors, where some (but not all) defendants choose to be grossly negligent; some (but not all) cases are filed; and, some lawsuits are dropped, some are resolved out-of-court and some go to trial. We then use this benchmark model to analyze the effects of court errors, damage caps, split-awards and fee-shifting. We find that court errors in assessing liability of negligent defendants, as well as damage caps and split-awards, reduce the likelihood of trial but increase filing and reduce the deterrence effect of punitive damages. We find conditions under which the adoption of the English rule for allocating legal costs reduces filing. Our model proves to be complete, i.e., it captures the main effects of tort reform of punitive damages, but tractable enough to be used as a tool for the analytical study of tort reform and court errors.

Our analysis has several policy implications. First, it points to the significance of the strategic behavior of plaintiff and defendant for the analysis of the effects of tort reform on deterrence. In particular, the analysis indicates that both damage caps and split-awards may reduce the expected loss for a grossly negligent defendant and therefore they may reduce deterrence. Second, the analysis underlines the importance of the defendant's care decision for the analysis of the effects of tort reform on filing and indicates that damage caps and split-awards may increase the plaintiff's expected payoff from suing by increasing the likelihood of confronting grossly negligent defendants. Therefore, caps and split-awards may increase filing of lawsuits.

Avenues for further research may involve an extension of this benchmark model by allowing the awards to depend also on the lawyer's effort. This model can be then used to evaluate the new method of lawyer's payment proposed by Polinsky and Rubinfeld (2003). Using an asymmetric information model of litigation, Polinsky and Rubinfeld (2003) show that this payment method aligns the interests of lawyers and clients, by providing the incentives to the lawyers to do exactly what a knowledgeable client would want him to do with respect to accepting the case, spending time on the case, and settling the case. However, their model does not allow for endogenous choice of level of care or court errors in assessing the liability of the defendant. 


\section{Appendix A. Proofs}

Proofs of Propositions 1-4, solution of the model of liability and litigation under the English rule, and proofs of Propositions 5 and 6 follow.

\section{Proof of Proposition 1.}

The proof has three main parts. In the first part, we prove the existence of the partially separating equilibria of the pre-trial bargaining subgame, under conditions (1)-(3). In the second part, we show that the partially separating equilibrium of the pre-trial bargaining subgame, proposed in Proposition 1, is the only partially separating equilibrium of the pre-trial bargaining stage that survives the universal divinity refinement and therefore, is the unique universal divine PBE of the pre-trial bargaining stage. In the third part, we complete the proof of the existence and uniqueness of the equilibrium of the whole game, proposed in Proposition 1. First, we prove that some but not all potential plaintiffs file a lawsuit; second, we show that some but not all potential injurers are grossly negligent; and, third, we prove that the described mixed-strategy equilibrium is the only equilibrium of the game.

Part 1. Existence of Perfect Bayesian Equilibria of the Litigation Game

Part 1.1. We eliminate the dominated and iteratively dominated strategies for each player.

Rationality suggests that since the plaintiff can get at most $\left(1-\tau_{1}\right) f A-K_{P}$ at trial, the plaintiff should accept any pretrial offer over $\left(1-\tau_{1}\right) f A-K_{P}$. That is, any strategy that calls for the plaintiff to reject an offer greater than $\left(1-\tau_{1}\right) f A-K_{P}$ is weakly dominated by a strategy in which he accepts the offer. ${ }^{44}$ Rationality also suggests, given that the plaintiff can drop the case and lose nothing, the plaintiff should reject any pretrial offer $S<0$. That is, any strategy that calls for the plaintiff to accept an offer lower than zero is dominated by a strategy in which he rejects the offer.

\footnotetext{
${ }^{44}$ It is only weakly dominated because the second strategy does not result in a strictly higher payoff against every one of the defendant's strategies. In particular, it does not result in a strictly higher payoff if the defendant's strategy is to refuse to offer a settlement (i.e., offer $S=0$ ) whether grossly negligent or no-grossly-negligent.
} 
Because the plaintiff accepts all offers over $\left(1-\tau_{1}\right) f A-K_{P}$ (maximum payoff at trial), any strategy in which the defendant offers more than $\left(1-\tau_{1}\right) f A-K_{P}$ when she is grossly negligent is iteratively dominated by a strategy in which she offers exactly $\left(1-\tau_{1}\right) f A-K_{P}$. Rationality also tells us that the defendant will offer no more than $K_{D}$ (loss for a no-grossly-negligent defendant at trial) if she is no-grossly-negligent. Finally, because the plaintiff rejects all offers below zero, any strategy in which the defendant offers less than zero is iteratively dominated by a strategy in which she offers exactly zero. Then, the minimum possible offer is $S=0$ and represents the defendant's refusal to settle.

Hence, after eliminating the dominated strategies and a first round of elimination of the iteratively dominated strategies for each player, we can restrict our attention to the offer space $\left[0,\left(1-\tau_{1}\right) f A-K_{P}\right]$ for the grossly negligent defendant (i.e., a proposal cannot be negative or greater than the maximum payoff the plaintiff can get in court); and, to the offer space $\left[0, \tau_{2} A+K_{D}\right]$, for the no-grossly-negligent defendant (i.e., a proposal cannot be negative or greater than the maximum loss the no-grossly-negligent defendant can get in court).

Let's apply iterative elimination of dominated strategies again. Because the no-grossly-negligent defendant never offers more than $\tau_{2} A+K_{D}$ and since the plaintiff can get $\left(1-\tau_{1}\right) f A-K_{P}$ at trial, rationality suggests that the plaintiff should reject any pretrial offer over $\tau_{2} A+K_{D}$ and lower than $\left(1-\tau_{1}\right) f A-K_{P}$. That is, any strategy that calls for the plaintiff to accept such an offer is iteratively dominated by a strategy in which he rejects the offer. Rationality also tells us that the grossly negligent defendant will not make any offer greater than $\tau_{2} A+K_{D}$ and lower than $\left(1-\tau_{1}\right) f A-K_{P}$. Then, the offer space for a grossly negligent defendant gets reduced to $\left[0, \tau_{2} A+K_{D}\right] \mathrm{U}\left\{\left(1-\tau_{1}\right) f A-K_{P}\right\}$

Part 1.2. We prove that in equilibrium the grossly negligent defendant randomizes at most between two possible strategies. In Part 1.1. we show that the offer space for the grossly negligent defendant is given by $\left[0, \tau_{2} A+K_{D}\right] U\left\{\left(1-\tau_{1}\right) f A-K_{P}\right\}$, then it suffices to show that there is no more than one equilibrium offer $S_{1} \in\left[0, \tau_{2} A+K_{D}\right] \cdot{ }^{45}$

\footnotetext{
${ }^{45}$ No more than one equilibrium offer $S_{1} \in\left[0, \tau_{2} A+K_{D}\right]$ implies that the grossly negligent defendant randomizes
} 
We consider 3 steps. First, we show that there is no equilibrium offer in this interval which is proposed by the grossly negligent defendant only. Second, we show that there is no equilibrium offer in the interval proposed by the no-grossly-negligent defendant only. Finally, we show that there is no two distinct equilibrium proposals proposed by both types of defendant.

\section{Part 1.2.1.}

If such an equilibrium offer $\tilde{S}$ existed, the plaintiff would reject it with probability 1 . Hence the case would be resolved at trial, and the grossly negligent defendant would lose $A+K_{D}$. He is better off offering $\left(1-\tau_{1}\right) f A-K_{P}$ which is accepted with certainty.

\section{Part 1.2.2.}

If such an equilibrium offer $\tilde{S}$ existed, then the plaintiff would accept it with probability 1 . Hence the grossly negligent defendant would be better off, switching to this offer.

\section{Part 1.2.3.}

We prove it by contradiction. Assume that there exist two such offers, $S_{1}$ and $S_{2}$, such that $0 \leq S_{1}<S_{2} \leq \tau_{2} A+K_{D}$. Denote by $p_{1}$ and $p_{2}$ the respective equilibrium probabilities of acceptance of these proposals by the plaintiff. Each type of defendant is indifferent between these proposals. Hence

$$
S_{1} p_{1}+\left(1-p_{1}\right)\left(\tau_{2} A+K_{D}\right)=S_{2} p_{2}+\left(1-p_{2}\right)\left(\tau_{2} A+K_{D}\right)
$$

and

$$
S_{1} p_{1}+\left(1-p_{1}\right)\left[\left(1-\tau_{1}\right) A+K_{D}\right]=S_{2} p_{2}+\left(1-p_{2}\right)\left[\left(1-\tau_{1}\right) A+K_{D}\right] .
$$

Subtracting the first equation from the second one, we get

$$
\left(1-p_{1}\right)\left(1-\tau_{1}-\tau_{2}\right) A=\left(1-p_{2}\right)\left(1-\tau_{1}-\tau_{2}\right) A
$$

Hence, $p_{1}=p_{2} \cdot{ }^{46}$ But in that case defendants of both types are strictly better off offering $S_{1}$. Contradiction follows.

at most between 2 possible strategies, one of which is $\left(1-\tau_{1}\right) f A-K_{P}$.

${ }^{46}$ The inequality $\tau_{1}+\tau_{2}<1$ holds by assumption (1). 
Part 1.3. We show that under conditions (1)-(3), there are infinitely many partially separating equilibria (one of them is the one stated in Proposition 1) and infinitely many pooling equilibria. ${ }^{47}$

Part 1.3.1. Existence of Partially Separating Equilibria of the Pre-Trial Bargaining Subgame The description of the partially separating equilibria is as follows. If conditions (1)-(3) hold: 1) no-grossly-negligent defendants offer $S_{1}$ such that $0 \leq S_{1} \leq \tau_{2} A+K_{D}$, and grossly negligent defendants mix the two strategies, offer $S_{1}$ with probability $\tilde{\beta}$ and offer $S_{2}=\left(1-\tau_{1}\right) f A-K_{P}$ with probability $(1-\tilde{\beta}) ; 2$ ) plaintiffs always file a lawsuit; plaintiffs always accept $S_{2}{ }^{48}$ and mix between rejection (with probability $\tilde{\alpha}$ ) and acceptance (with probability $(1-\tilde{\alpha})$ when the offer is $S_{1}$ such that $0<S_{1} \leq \tau_{2} A+K_{D} \cdot{ }^{49}$

Consider the expected payoffs for the plaintiff, no-grossly-negligent and grossly negligent defendants, in terms of $\tilde{\alpha}$ and $\tilde{\beta}$. The expected payoff for the plaintiff $V_{P}$ is

$V_{P}=(1-q)\left[\tilde{\alpha}\left(\tau_{2} f A-K_{P}\right)+(1-\tilde{\alpha})\left(S_{1}\right)\right]+q\left\{\tilde{\beta}\left[\tilde{\alpha}\left[\left(1-\tau_{1}\right) f A-K_{P}\right]+(1-\tilde{\alpha})\left(S_{1}\right)\right]+(1-\tilde{\beta})\left[\left(1-\tau_{1}\right) f A-K_{P}\right]\right\}$.

The expected payoff for the no-grossly-negligent defendant $V_{D_{1}}$ is

$$
V_{D^{1}}=\tilde{\alpha}\left(-\tau_{2} A-K_{D}\right)+(1-\tilde{\alpha})\left(S_{1}\right)
$$

And, the expected payoff for the grossly negligent defendant, $V_{D^{0}}$ is

$$
V_{D^{0}}=\tilde{\beta}\left[\tilde{\alpha}\left(-\left(\left(1-\tau_{1}\right) A+K_{D}\right)\right)+(1-\tilde{\alpha})\left(S_{1}\right)\right]+(1-\tilde{\beta})\left[-\left(\left(1-\tau_{1}\right) f A-K_{P}\right)\right] .
$$

The values of $\tilde{\alpha}$ and $\tilde{\beta}$ are calculated from the condition that both parties (the plaintiff and the grossly negligent defendant) have to be indifferent between their strategies to mix them. So,

$$
\left(1-\tau_{1}\right) f A-K_{P}=\tilde{\alpha}\left(\left(1-\tau_{1}\right) A+K_{D}\right)+(1-\tilde{\alpha}) S_{1}
$$

\footnotetext{
${ }^{47}$ Condition $0<\left[q\left(1-\tau_{1}\right)+(1-q) \tau_{2}\right] f A-K_{P}<K_{F}$ rules out the equilibrium where no lawsuit is filed; and, condition $\left(1-\tau_{1}\right) f A-K_{P}>\tau_{2} A+K_{D}$ rules out the pooling equilibrium where the no-grossly-negligent defendant behaves as a grossly negligent defendant by making a positive settlement offer.

A separating equilibrium is not possible in this game. Suppose that a separating equilibrium exists: no-grosslynegligent defendants offer $S_{1} \leq \tau_{2} A+K_{D}$ and grossly negligent defendants offer $S_{2} \neq S_{1}$. Given that $S_{1}$ is always accepted by the plaintiff and $S_{2}$ is always rejected by the plaintiff, then the grossly negligent defendant has an incentive to deviate to $S_{1}$ because $S_{1}<\left(1-\tau_{1}\right) A+K_{D}$.

${ }^{48} \mathrm{~A}$ defendant offering $S_{2}$ reveals his type, and hence $S_{2}$ should be equal to $\left(1-\tau_{1}\right) f A-K_{P}$ to be always accepted.

${ }^{49}$ As the plaintiff accepts some of the offers of $S_{1}$, a grossly negligent defendant has an incentive to mimic the behavior of the no-grossly-negligent defendant and offer $S_{1}$ as well.
} 
and

$$
S_{1}=\frac{q \tilde{\beta}}{q \tilde{\beta}+(1-q)}\left(\left(1-\tau_{1}\right) f A-K_{P}\right)+\frac{1-q}{q \tilde{\beta}+(1-q)}\left(\tau_{2} f A-K_{P}\right)
$$

Equation (A4) says that a grossly negligent defendant is indifferent between admitting his negligence (i.e., offering $\left.S_{2}=\left(1-\tau_{1}\right) f A-K_{P}\right)$ and stating that he is no-grossly-negligent (i.e., offering $\left.S_{1}\right)$ with the risk to lose $\left(1-\tau_{1}\right) A+K_{D}$ if the case goes to court. Equation (A5) says that a plaintiff is indifferent between dropping the case and getting a payoff of $S_{1}$ and going to court. Solving (A4) for $\tilde{\alpha}$ and (A5) for $\tilde{\beta}$ we get $\tilde{\alpha}=\frac{\left(1-\tau_{1}\right) f A-K_{P}-S_{1}}{\left(1-\tau_{1}\right) A+K_{D}-S_{1}}$ and $\tilde{\beta}=\frac{\left(S_{1}+K_{P}-\tau_{2} f A\right)(1-q)}{q\left(\left(1-\tau_{1}\right) f A-S_{1}-K_{P}\right)} \cdot{ }^{50}$

Then, the expected payoffs for the plaintiff, grossly negligent, and no-grossly-negligent defendant are $V_{P}=\left[q\left(1-\tau_{1}\right)+\tau_{2}(1-q)\right] f A-K_{P}, V_{D^{0}}=-\left[\left(1-\tau_{1}\right) f A-K_{P}\right]$, and $V_{D^{1}}=-\left\{\frac{S_{1}\left[\left(1-\tau_{1}\right)(1-f) A+K_{P}+K_{D}\right]+\left[\left(1-\tau_{1}\right) f A-K_{P}-S_{1}\right]\left(\tau_{2} A+K_{D}\right)}{\left(1-\tau_{1}\right) A+K_{D}-S_{1}}\right\}$, respectively.

The equilibrium beliefs are as follows. If an accident occurs, the plaintiff believes with probability $(1-q)$ that she is confronting a no-grossly-negligent defendant, and with probability $q$ that she is confronting a grossly negligent defendant. When the plaintiff receives an offer, she updates her beliefs using Bayes' rule: when she receives an offer $S_{1}$, she believes with probability $\frac{(1-q)}{q \tilde{\beta}+(1-q)}$ that she is confronting a no-grossly-negligent defendant and with probability $\frac{q \tilde{\beta}}{q \tilde{\beta}+(1-q)}$ that she is confronting a grossly negligent defendant; when the plaintiff receives an offer $S_{2}$, she believes with certainty that she is confronting a grossly negligent defendant.

The off-equilibrium beliefs are as follows. When the plaintiff observes an offer $S^{\prime}<S_{1}$ or an offer $S_{1}<S^{\prime}<\left(1-\tau_{1}\right) f A-K_{P}$, she believes that she faces a grossly negligent defendant. Then, the plaintiff rejects the offer with certainty because she will obtain a higher payoff $\left(\left(1-\tau_{1}\right) f A-K_{P}\right)$ if she brings the grossly negligent defendant to trial. Given that $S^{\prime}$ is rejected with certainty, the no-grossly-negligent defendant will not make the offer $S^{\prime}$ because he will receive a higher payoff by offering $S_{1}$, which is accepted with positive probability in the proposed equilibrium. Given that the plaintiff will reject the offer $S^{\prime}$ with certainty, the grossly negligent defendant will not make an offer $S^{\prime}$ because he will receive a higher payoff by offering $S_{2}=\left(1-\tau_{1}\right) f A-K_{P}$ with probability

\footnotetext{
${ }^{50}$ Note that $\tilde{\alpha}\left(S_{1}=0\right)=\alpha$ and $\tilde{\beta}\left(S_{1}=0\right)=\beta$, i.e., the equilibrium path just described corresponds to the partially separating perfect Bayesian equilibrium stated in Proposition 1.
} 
$(1-\tilde{\beta})$ and $S_{1}$ with probability $\tilde{\beta}$ (as stated in the proposed equilibrium).

Part 1.3.2. Existence of Pooling Equilibria of the Pre-Trial Bargaining Subgame

The description of the pooling equilibria is as follows. If $\left[q\left(1-\tau_{1}\right)+(1-q) \tau_{2}\right] f A-K_{P}>0$ and $\left.\left(1-\tau_{1}\right) f A-K_{P}>\tau_{2} A+K_{D}: 1\right)$ grossly negligent and no-grossly-negligent defendants offer the same amount $S$, where $0<S \leq \tau_{2} A+K_{D}$ and $\left.S \geq\left[q\left(1-\tau_{1}\right)+(1-q) \tau_{2}\right] f A-K_{P} ; 2\right)$ plaintiffs always file a lawsuit; plaintiffs always accept the offer $S .{ }^{51}$

The equilibrium beliefs are as follows. If an accident occurs, the plaintiff believes with probability $(1-q)$ that she is confronting a no-grossly-negligent defendant, and with probability $q$ that she is confronting a grossly negligent defendant. Given that defendants pool, when the plaintiff receives an offer, she cannot update her beliefs. Then, the plaintiff accepts if the offer is greater than or equal to her ex-ante expected return from trial $\left(S \geq\left[q\left(1-\tau_{1}\right)+(1-q) \tau_{2}\right] f A-K_{P}\right) .{ }^{52}$ The off-equilibrium beliefs compatible with this equilibrium are as follows. If the defendant offers $\tilde{S} \neq S$, then the plaintiff believes with certainty that he faces the grossly negligent defendant and rejects the offer.

Part 2. Uniqueness of the Pre-Trial Bargaining Subgame Equilibrium

We prove that the PBE stated in Proposition 1 is the only PBE that survives the universal divinity refinement is the partially separating $\mathrm{PBE}$, and therefore, this is the unique equilibrium of the litigation stage. We proceed first to apply the universal divinity refinement to the partially separating equilibria, and second, to the pooling equilibria. The implementation of the universal divinity refinement proceeds as follows. First, we find (for no-grossly-negligent and grossly negligent defendants) the minimum probability of acceptance (by the plaintiff) of an offer that differs from

\footnotetext{
${ }^{51}$ if $S \leq \tau_{2} A+K_{D}$ fails to hold, the no-grossly-negligent defendant will find it optimal to deviate, to offer 0 , and go to trial; if $S \geq\left[q\left(1-\tau_{1}\right)+(1-q) \tau_{2}\right] f A-K_{P}$ fails to hold, the plaintiff will find it profitable to deviate and reject the proposal $S$.

Note also that there is no possible pooling with $S=0$ and plaintiff accepting the offer with certainty: if every defendant offers $S=0$, then the plaintiff will be better off by rejecting the offer because $\left[q\left(1-\tau_{1}\right)+(1-q) \tau_{2}\right] f A-K_{P}>$ 0, i.e., her ex-ante expected payoff from going to trial is greater than the offer. Then, it would be optimal for the grossly negligent defendant to deviate from offering $S=0$ to $S^{\prime}=\left(1-\tau_{1}\right) f A-K_{P}<\left(1-\tau_{1}\right) A+K_{D}$ (loss at trial).

${ }^{52}$ The plaintiff computes the ex-ante return from trial by using her prior beliefs and the payoffs at trial from confronting grossly negligent and no-grossly-negligent defendants. So, the ex-ante return from trial $q\left[\left(1-\tau_{1}\right) f A-\right.$ $\left.K_{P}\right)+(1-q)\left(\tau_{2} f A-K_{P}\right)=\left[q\left(1-\tau_{1}\right)+(1-q) \tau_{2}\right] f A-K_{P}$
} 
the equilibrium offers (deviation offer), such that the defendant is willing to deviate. Second, we compare these minimum probabilities. The defendant with the lower minimum probability will be the one the plaintiff should expect (with probability one) to deviate.

Part 2.1. Elimination of the Other Partially Separating Equilibria

Consider the deviation $S^{\prime}$ from an equilibrium offer $S_{1}$ or $S_{2}$. We will cover the analysis of three cases: $0 \leq S^{\prime}<\tau_{2} A+K_{D}, S^{\prime}=\tau_{2} A+K_{D}$ and $\tau_{2} A+K_{D}<S^{\prime}<f A-K P$.

Case I: $0 \leq S^{\prime}<\tau_{2} A+K_{D}$

For mathematical convenience, define $S^{\prime}=S_{1}-\epsilon$. If $\epsilon<0$, then the deviation offer $S^{\prime}>S_{1}$; and, if $\epsilon>0$, then the deviation offer $S^{\prime}<S_{1}$.

Proceed first to analyze the case of the grossly negligent defendant. The grossly negligent defendant will be willing to deviate if

$$
p_{N}\left(S_{1}-\epsilon\right)+\left(1-p_{N}\right)\left(\left(1-\tau_{1}\right) A+K_{D}\right) \leq\left[\left(1-\tau_{1}\right) f A-K_{P}\right]
$$

where the left-hand side of the inequality represents the expected loss for the grossly negligent defendant from deviating and the right-hand side represents his expected loss in equilibrium. ${ }^{53}$ Solving for $p_{N}$ we get

$$
p_{N} \geq \frac{\left(1-\tau_{1}\right)(1-f) A+K_{P}+K_{D}}{\left(1-\tau_{1}\right) A+K_{D}-S_{1}+\epsilon} .
$$

Then, the minimum probability of acceptance of the deviation offer made by the grossly negligent defendant is

$$
\underline{p_{N}}=\frac{\left(1-\tau_{1}\right)(1-f) A+K_{P}+K_{D}}{\left(1-\tau_{1}\right) A+K_{D}-S_{1}+\epsilon} .
$$

Now find the minimum probability of acceptance of the deviation by the plaintiff, such that the no-grossly-negligent defendant is still willing to propose it.

$$
p_{C}\left(S_{1}-\epsilon\right)+\left(1-p_{C}\right)\left(\tau_{2} A+K_{D} \leq\right.
$$

\footnotetext{
${ }^{53}$ Note that in every partially separating PBE of the litigation game (under the conditions $q f A-K_{P}>0$ and $\left.f A-K_{P}>K_{D}\right)$ the expected payoff for the grossly negligent defendant is $f A-K_{P}$.
} 


$$
\leq\left[S_{1}\left(1-\frac{\left(1-\tau_{1}\right) f A-K_{P}-S_{1}}{\left(1-\tau_{1}\right) A+K_{D}-S_{1}}\right)+\left(\tau_{2} A+K_{D}\right) \frac{\left(1-\tau_{1}\right) f A-K_{P}-S_{1}}{\left(1-\tau_{1}\right) A+K_{D}-S_{1}}\right]
$$

where the left-hand side of the inequality represents the expected loss for the no-grossly-negligent defendant from deviating and the right-hand side represents his expected loss in equilibrium. ${ }^{54}$ Solving for $p_{C}$ we get

$$
\begin{gathered}
p_{C} \geq \frac{\tau_{2} A+K_{D}}{\tau_{2} A+K_{D}-S_{1}+\epsilon}- \\
-\frac{\left[\left(1-\tau_{1}\right)(1-f) A+K_{P}+K_{D}\right] S_{1}+\left[\left(1-\tau_{1}\right) f A-K_{P}-S_{1}\right]\left(\tau_{2} A+K_{D}\right)}{\left[\left(1-\tau_{1}\right) A+K_{D}-S_{1}\right]\left(\tau_{2} A+K_{D}-S_{1}+\epsilon\right)}
\end{gathered}
$$

Then, the minimum probability of acceptance of the deviation offer made by the no-grossly-negligent defendant is

$$
\begin{gathered}
\underline{p_{C}}=\frac{\tau_{2} A+K_{D}}{\tau_{2} A+K_{D}-S_{1}+\epsilon}- \\
-\frac{\left[\left(1-\tau_{1}\right)(1-f) A+K_{P}+K_{D}\right] S_{1}+\left[\left(1-\tau_{1}\right) f A-K_{P}-S_{1}\right]\left(\tau_{2} A+K_{D}\right)}{\left[\left(1-\tau_{1}\right) A+K_{D}-S_{1}\right]\left(\tau_{2} A+K_{D}-S_{1}+\epsilon\right)}
\end{gathered}
$$

Compare the threshold probabilities for the grossly negligent and no-grossly-negligent defendant.

$$
\begin{aligned}
& \underline{p_{C}}-\underline{p_{N}}=\frac{\tau_{2} A+K_{D}}{\tau_{2} A+K_{D}-S_{1}+\epsilon}- \\
& -\frac{\left[\left(1-\tau_{1}\right)(1-f) A+K_{P}+K_{D}\right] S_{1}+\left[\left(1-\tau_{1}\right) f A-K_{P}-S_{1}\right]\left(\tau_{2} A+K_{D}\right)}{\left[\left(1-\tau_{1}\right) A+K_{D}-S_{1}\right]\left(\tau_{2} A+K_{D}-S_{1}+\epsilon\right)}- \\
& -\frac{\left(1-\tau_{1}\right)(1-f) A+K_{P}+K_{D}}{\left(1-\tau_{1}\right) A+K_{D}-S_{1}+\epsilon}= \\
& =\frac{-A\left(1-\tau_{1}-\tau_{2}\right) \epsilon\left[\left(1-\tau_{1}\right)(1-f) A+K_{D}+K_{P}\right]}{\left(\left(1-\tau_{1}\right) A+K_{D}-S_{1}\right)\left(\tau_{2} A+K_{D}-S_{1}+\epsilon\right)\left(\left(1-\tau_{1}\right) A+K_{D}-S_{1}+\epsilon\right)},
\end{aligned}
$$

where the expressions in bracket and parentheses are positive. Then, if $\epsilon<0, \underline{p_{N}}<\underline{p_{C}}$; and, if $\epsilon>0, \underline{p_{N}}>\underline{p_{C}}$

Following the universal divinity refinement, if $0 \leq S^{\prime}<\tau_{2} A+K_{D}$ and $\epsilon<0\left(S^{\prime}>S_{1}\right)$, the plaintiff should believe that the deviation $S^{\prime}$ comes from a grossly negligent defendant with

\footnotetext{
${ }^{54}$ Remember that $\tilde{\alpha}\left(S_{1}=0\right)=\alpha$. Given that we need to apply the results of this proof to check all partially separating PBE of the litigation game, we will use $\tilde{\alpha}$ in the computation of the expected payoff for the no-grosslynegligent defendant. Note that in every partially separating PBE of the litigation game (under the conditions $q f A-K_{P}>0$ and $\left.f A-K_{P}>K_{D}\right)$ the expected payoff for the no-grossly-negligent defendant does depend on $S_{1}$.
} 
probability one. On the other hand, if $\epsilon>0\left(S^{\prime}<S_{1}\right)$, the plaintiff should believe with probability one that the deviation $S^{\prime}$ comes from a no-grossly-negligent defendant.

Apply the universal divinity refinement to the other partially separating equilibria (where $0<$ $\left.S_{1} \leq K_{D}\right)$. The off-equilibrium beliefs imply that the plaintiff should infer that any deviation $S^{\prime}$ comes from a grossly negligent defendant. In case of $\epsilon>0\left(S^{\prime}<S_{1}\right)$, these off-equilibrium beliefs do not survive the refinement. The plaintiff should believe that the deviation comes from a no-grosslynegligent defendant and accept the offer. This response from the plaintiff will generate an incentive for the grossly negligent defendant to deviate and offer $S_{1}-\epsilon$. Hence, the other partially separating equilibria (where $0<S_{1} \leq K_{D}$ ) do not pass the test of universal divinity for $0 \leq S^{\prime}<\tau_{2} A+K_{D}$.

We will apply now the universal divinity refinement to the empirically relevant equilibrium (where $S_{1}=0$ ). The off-equilibrium beliefs imply that the plaintiff should infer that any deviation comes from a grossly negligent defendant. Note also that given that $S_{1}=0$ is the lowest possible offer, only deviations above $S_{1}$ (i.e., $S^{\prime}>S_{1}$ ) are possible. Therefore, the off-equilibrium beliefs survive the universal divinity refinement. Hence, the empirically relevant equilibrium passes the test of universal divinity for $0 \leq S^{\prime}<\tau_{2} A+K_{D}$.

Case II: $S^{\prime}=K_{D}$

The minimum probability of acceptance of a deviation offer made by the grossly negligent defendant is still given by equation (A8).

For the case of the no-grossly-negligent defendant, note that his expected deviation loss is $\tau_{2} A+K_{D}$ and his expected equilibrium loss is in the interval $\left(\frac{\left(1-\tau_{1}\right) f A-K_{P}}{\left(1-\tau_{1}\right) A+K_{D}}\left(\tau_{2} A+K_{D}\right), \tau_{2} A+K_{D}\right)$ (for $0<S_{1}<\tau_{2} A+K_{D}$ ) and is equal to $\frac{\left(1-\tau_{1}\right) f A-K_{P}}{\left(1-\tau_{1}\right) A+K_{D}}<\tau_{2} A+K_{D}$ (for $S_{1}=0$ ). Then, for any probability of acceptance, the no-grossly-negligent defendant will not be willing to deviate when $S^{\prime}=\tau_{2} A+K_{D}$

By universal divinity, the plaintiff should expect that any deviation offer $S^{\prime}=\tau_{2} A+K_{D}$ comes from a grossly negligent defendant. Thus, all partially separating PBE pass the test of universal divinity for $S^{\prime}=\tau_{2} A+K_{D}$. 
Given that the partially separating PBE stated in Proposition 1 is the only partially separating equilibrium that survives the universal divinity refinement in both cases, then the equilibrium proposed in Proposition 1 is the only universal divine partially separating PBE.

Part 2.2. Elimination of the Pooling Equilibria

Consider the deviation $S^{\prime}$ from an equilibrium offer $S$. We will cover the analysis of two cases: $0 \leq S^{\prime}<\tau_{2} A+K_{D}$ and $S^{\prime}=\tau_{2} A+K_{D}$.

Case I: $0 \leq S^{\prime}<\tau_{2} A+K_{D}$

For mathematical convenience, define $S^{\prime}=S-\epsilon$. If $\epsilon<0$, then the deviation offer $S^{\prime}>S$; and, if $\epsilon>0$, then the deviation offer $S^{\prime}<S$.

Proceed first to analyze the case of the grossly negligent defendant. The grossly negligent defendant will be willing to deviate if

$$
p_{N}(S-\epsilon)+\left(1-p_{N}\right)\left[\left(1-\tau_{1}\right) A+K_{D}\right) \leq S,
$$

where the left-hand side of the inequality represents the expected loss for the grossly negligent defendant from deviating and the right-hand side represents his expected loss in equilibrium. ${ }^{55}$ Solving for $p_{N}$ we get

$$
p_{N} \geq \frac{\left(1-\tau_{1}\right) A+K_{D}-S}{\left(1-\tau_{1}\right) A+K_{D}-S+\epsilon} .
$$

Then, the minimum probability of acceptance of the deviation offer made by the grossly negligent defendant is

$$
\underline{p_{N}}=\frac{\left(1-\tau_{1}\right) A+K_{D}-S}{\left(1-\tau_{1}\right) A+K_{D}-S+\epsilon}
$$

Now find the minimum probability of acceptance of the deviation by the plaintiff, such that the no-grossly-negligent defendant is still willing to propose it.

$$
p_{C}(S-\epsilon)+\left(1-p_{C}\right)\left(\tau_{2} A+K_{D}\right) \leq S
$$

\footnotetext{
${ }^{55}$ Note that in every pooling PBE of the litigation game (under the conditions $q f A-K_{P}>0$ and $f A-K_{P}>K_{D}$ ) the expected payoff for the grossly negligent defendant is $S$.
} 
where the left-hand side of the inequality represents the expected loss for the no-grossly-negligent defendant from deviating and the right-hand side represents his expected loss in equilibrium. Solving for $p_{C}$ we get

$$
p_{C} \geq \frac{\tau_{2} A+K_{D}-S}{\tau_{2} A+K_{D}-S+\epsilon} .
$$

Then, the minimum probability of acceptance of the deviation offer made by the no-grossly-negligent defendant is

$$
\underline{p_{C}}=\frac{\tau_{2} A+K_{D}-S}{\tau_{2} A+K_{D}-S+\epsilon} .
$$

Note that inspection of equations (A21) and (A18) show that if $\epsilon<0$, the left-hand side of the inequalities will be greater than 1 . Given that the right-hand side of the inequalities correspond to probabilities (which cannot be greater than 1), the inspection of these equations permits us to conclude that the universal divinity refinement is not applicable for cases where $\epsilon<0$. Then, we will proceed to the application of the universal divinity refinement only in cases where $\epsilon>0$.

Compare the threshold probabilities for the grossly negligent and no-grossly-negligent defendant.

$$
\underline{p_{C}}-\underline{p_{N}}=\frac{-A \epsilon\left(1-\tau_{1}-\tau_{2}\right)}{\left(\tau_{2} A+K_{D}-S+\epsilon\right)\left(\left(1-\tau_{1}\right) A+K_{D}-S+\epsilon\right)},
$$

where $A$ and the expressions in parentheses are positive. Then, if $\epsilon>0, \underline{p_{N}}>\underline{p_{C}}$.

Following the universally divinity refinement, if $0 \leq S^{\prime}<\tau_{2} A+K_{D}$ and $\epsilon>0\left(S^{\prime}<S\right)$, the plaintiff should believe with probability one that the deviation $S^{\prime}$ comes from a no-grossly-negligent defendant.

Apply the universal divinity refinement to the pooling equilibria (where $0<S \leq \tau_{2}+K_{D}$ ). The off-equilibrium beliefs imply that the plaintiff should infer that any deviation $S^{\prime}$ comes from a grossly negligent defendant. These off-equilibrium beliefs do not survive the refinement. The plaintiff should believe that the deviation comes from a no-grossly-negligent defendant and accept the offer. This response from the plaintiff will generate an incentive for the grossly negligent defendant to deviate and offer $S-\epsilon$. Hence, the pooling equilibria (where $0<S \leq \tau_{2} A+K_{D}$ ) do not pass the test of universal divinity for $0 \leq S^{\prime}<\tau_{2} A+K_{D}$.

Case II: $S^{\prime}=K_{D}$ 
The minimum probability of acceptance of a deviation offer made by the grossly negligent defendant is still given by equation (A11).

For the case of the no-grossly-negligent defendant, note that his expected deviation loss is $K_{D}$ and his expected equilibrium loss is in the interval $\left(\frac{f A-K_{P}}{A+K_{D}}, K_{D}\right)$ (for $0<S<K_{D}$ ) and is equal to $\frac{f A-K_{P}}{A+K_{D}}<K_{D}$ (for $S=0$ ). Then, for any probability of acceptance, the no-grossly-negligent defendant will not be willing to deviate when $S^{\prime}=K_{D}$.

By universal divinity, the plaintiff should expect that any deviation offer $S^{\prime}=K_{D}$ comes from a grossly negligent defendant. Thus, all pooling PBE pass the test of universal divinity for $S^{\prime}=\tau_{2} A+K_{D}$

Given that no pooling PBE survive the universal divinity refinement in both cases, there is no universal divine pooling PBE.

Hence, the partially separating PBE stated in Proposition 1 is the unique universally divine PBE of the litigation stage. Q.E.D.

Part 3. Existence and Uniqueness of the Game Equilibrium

In the third part, we prove that some but not all potential plaintiffs file a lawsuit, that some but not all potential injurers are grossly negligent, and that the described mixed-strategy equilibrium is the only equilibrium of the game.

Part 3.1. Some But Not All Potential Plaintiffs File A Lawsuit

We prove that $0<m<1$. The proof has two parts.

Part 3.1.1. $m>0$

Given that $m=\frac{c}{\left.\left[\left(1-\tau_{1}\right) f A-K_{P}\right)\right]\left[\lambda^{0}-\lambda^{1} \frac{\left(\tau_{2} A+K_{D}\right)}{\left(1-\tau_{1}\right) A+K_{D}}\right]}$, it suffices to show that $\left[\lambda^{0}-\lambda^{1} \frac{\left(\tau_{2} A+K_{D}\right)}{\left(1-\tau_{1}\right) A+K_{D}}\right]>$ 0 . By assumption, $\lambda^{0}>\lambda^{1}$; and by condition (1), $\tau_{2} A+K_{D}<\left(1-\tau_{1}\right) f A-K_{P}$. Then, $\tau_{2} A+K_{D}<$ $\left(1-\tau_{1}\right) f A-K_{P}<\left(1-\tau_{1}\right) A+K_{D}$. Hence, $\frac{\tau_{2} A+K_{D}}{\left(1-\tau_{1}\right) A+K_{D}}<1$. Q.E.D.

Part 3.1.2. $m<1$ 
We will prove that $m<1$ if and only if $\tau_{1}<\overline{\tau_{1}}=1-\frac{-B_{1}+\sqrt{B_{1}^{2}+4 A_{1} C_{1}}}{2 A_{1}}$, where $A_{1}=f A^{2} \lambda^{0}$, $B_{1}=f A K_{D}\left(\lambda^{0}-\lambda^{1}\right)-A\left(K_{P}+\lambda^{1}+c\right)$, and $C_{1}=\left(\lambda^{0}-\lambda^{1}\right) L_{P} K_{D}+c K_{D}$ and $\tau_{2}<\overline{\tau_{2}}\left(\tau_{1}\right)=$ $\frac{\left(1-\tau_{1}\right) A+K_{D}}{\lambda^{1} A}\left[\lambda^{0}-\frac{\left(1-\tau_{1}\right) F A-K_{P}}{c}\right]-\frac{K_{D}}{A}$

First, we show that $m$ is increasing in $\tau_{1}$ and $\tau_{2}$. Next, we compute $\overline{\tau_{1}}$ and $\overline{\tau_{2}}$.

\section{Part 3.1.2.1.}

Differentiating $m$, the probability of filing, equation (14), with respect to $\tau_{1}$, yields

$$
\begin{gathered}
\frac{\partial m}{\partial \tau_{1}}=-\frac{c}{\left[\left(1-\tau_{1}\right) f A-K_{P}\right]^{2}\left[\lambda^{0}-\lambda^{1} \frac{\left(\tau_{2} A+K_{D}\right)}{\left(1-\tau_{1}\right) A+K_{D}}\right]^{2}}\left[-f A\left(\lambda^{0}-\lambda^{1} \frac{\left(\tau_{2} A+K_{D}\right)}{\left(1-\tau_{1}\right) A+K_{D}}\right)+\right. \\
\left.+\left[\left(1-\tau_{1}\right) f A-K_{P}\right] \frac{\left(\tau_{2} A+K_{D}\right)}{\left[\left(1-\tau_{1}\right) A+K_{D}\right]^{2}}(-A)\right]>0 .
\end{gathered}
$$

Differentiating $m$, equation (12), with respect to $\tau_{2}$ yields

$$
\frac{\partial m}{\partial \tau_{2}}=-\frac{c}{\left[\left(1-\tau_{1}\right) f A-K_{P}\right]\left[\lambda^{0}-\lambda^{1} \frac{\tau_{2} A+K_{D}}{\left(1-\tau_{1}\right) A+K_{D}}\right]^{2}}\left[-\lambda^{1} \frac{A}{\left(1-\tau_{1}\right) A+K_{D}}\right]>0 .
$$

Hence, an increase in $\tau_{1}$ or $\tau_{2}$ raise filing.

\section{Part 3.1.2.2.}

1) Computation of $\overline{\tau_{1}}$.

The maximum feasible range of $\tau_{1}$ consistent with $m<1$ is attained if $\tau_{2}=0$. Given that $m$ is increasing in $\tau_{1}, m<1$ if and only if $\tau_{1}<\overline{\tau_{1}}$, where $\overline{\tau_{1}}$ is defined implicitly by $m\left(\tau_{1}=\overline{\tau_{1}}, \tau_{2}=0\right)=1$.

The condition $m\left(\tau_{1}=\overline{\tau_{1}}, \tau_{2}=0\right)=1$ can be rewritten as:

$$
\frac{c}{\left[\left(1-\overline{\tau_{1}}\right) f A-K_{P}\right]\left[\lambda^{0}-\lambda^{1} \frac{K_{D}}{\left(1-\overline{\tau_{1}}\right) A+K_{D}}\right]}=1
$$

After some straightforward algebraic manipulations the last equation becomes:

$$
A_{1}\left(1-\overline{\tau_{1}}\right)^{2}+B_{1}\left(1-\overline{\tau_{1}}\right)-C_{1}=0
$$

where $A_{1} \equiv f A^{2} \lambda^{0}>0, B_{1} \equiv f A \lambda^{0} K_{D}-A K_{P} \lambda^{1}-C A-\lambda^{1} f A K_{D}$, and $C_{1} \equiv\left(\lambda^{0}-\lambda^{1}\right) K_{P} K_{D}+$ $c K_{D}>0$. 
Equation (A26) is a quadratic equation in $1-\tau_{1}$. It has two roots, $1-\tau_{1}^{1}$ and $1-\tau_{1}^{2}$, such that $\left(1-\tau_{1}^{1}\right)\left(1-\tau_{1}^{2}\right)=-\frac{C_{1}}{A_{1}}<0$. Hence, one root is negative, and the other one is positive. The negative value of $1-\tau_{1}$ means that $\tau_{1}>1$, which is impossible. Hence, to calculate $\overline{\tau_{1}}$, we need to calculate the positive (the larger) root of the equation (A26). Therefore,

$$
1-\bar{\tau}_{1}=\frac{-B_{1}+\sqrt{B_{1}^{2}+4 A_{1} C_{1}}}{2 A_{1}}
$$

and

$$
\bar{\tau}_{1}=1-\frac{-B_{1}+\sqrt{B_{1}^{2}+4 A_{1} C_{1}}}{2 A_{1}} .
$$

2) Computation of $\overline{\tau_{2}}$.

Given that $m$ is increasing in $\tau_{2}$ for any given $\tau_{1}, m<1$ if and only if $\tau_{2}<\overline{\tau_{2}}\left(\tau_{1}\right)$, where $\overline{\tau_{2}}\left(\tau_{1}\right)$ is defined implicitly by $m\left(\tau_{1}, \tau_{2}=\overline{\tau_{2}}\left(\tau_{1}\right)\right)=1$.

The last equation can be rewritten as:

$$
\frac{c}{\left[\left(1-\tau_{1}\right) f A-K_{P}\right]\left[\lambda^{0}-\lambda^{1} \frac{\overline{\tau_{2}} A+K_{D}}{\left(1-\tau_{1}\right) A+K_{D}}\right]}=1 .
$$

Solving the last equation for $\overline{\tau_{2}}$ yields

$$
\overline{\tau_{2}}=\frac{\left(1-\tau_{1}\right) A+K_{D}}{\lambda^{1} A}\left[\lambda^{0}-\frac{\left(1-\tau_{1}\right) f A-K_{P}}{C_{1}}\right]-\frac{K_{D}}{A}
$$

Q.E.D.

Part 3.2. Some But Not All Potential Injurers Are Grossly Negligent

We prove that $0<q<1$

By condition $(3), K_{P}>\tau_{2} f A$. Then, $0<q$. In addition, condition (2) implies that $q<1$. Q.E.D.

Part 3.3. Uniqueness of the Game Equilibrium

We prove that the described mixed-strategy equilibrium is the only equilibrium of the game. Suppose that the probability of being no-grossly-negligent is greater than the one set by equation (15) (it can be equal to one), i.e. $\tilde{p}>p$. This will imply a lower conditional (on the occurrence 
of the accident) probability that the defendant is grossly negligent, $\tilde{q}<q$, determined by equation (14). Given that the expected payoff of the plaintiff, $\left[q\left(1-\tau_{1}\right)+(1-q) \tau_{2}\right] f A-K_{P}$ depends positively on $q$, it will be lower as well. Hence, the probability of filing $m$ will be also lower. But in that case, the left-hand side of equation (10) will be greater than the right-hand side. Therefore, it will be optimal for all prospective defendants not to take care, which contradicts the initial assumption that $\tilde{p}>p$. The impossibility of the opposite case, $\tilde{p}<p$ can be shown similarly. Q.E.D. 
Proof of Proposition 2.

Differentiating $m$, the probability of filing, equation (16), with respect to $\tau_{1}$, yields

$$
\begin{gathered}
\frac{\partial m}{\partial \tau_{1}}=-\frac{c}{\left[\left(1-\tau_{1}\right) f A-K_{P}\right]^{2}\left[\lambda^{0}-\lambda^{1} \frac{\left(\tau_{2} A+K_{D}\right)}{\left(1-\tau_{1}\right) A+K_{D}}\right]^{2}}\left[-f A\left(\lambda^{0}-\lambda^{1} \frac{\left(\tau_{2} A+K_{D}\right)}{\left(1-\tau_{1}\right) A+K_{D}}\right)+\right. \\
\left.+\left[\left(1-\tau_{1}\right) f A-K_{P}\right] \frac{\left(\tau_{2} A+K_{D}\right)}{\left[\left(1-\tau_{1}\right) A+K_{D}\right]^{2}}(-A)\right]>0 .
\end{gathered}
$$

Hence, an increase in $\tau_{1}$ raises filing.

Differentiating $q$, equation (18), with respect to $\tau_{1}$ yields

$$
\frac{\partial q}{\partial \tau_{1}}=\frac{\left(F^{-1}(m)\right)^{\prime} \frac{\partial m}{\partial \tau_{1}} f A\left(1-\tau_{1}-\tau_{2}\right)+f A\left(F^{-1}(m)+K_{P}-\tau_{2} f A\right)}{\left[f A\left(1-\tau_{1}-\tau_{2}\right]^{2}\right.}>0
$$

because $\tau_{1}+\tau_{2}<1$.

Differentiating equation (20) with respect to $\tau_{1}$, we get

$$
\frac{\partial p}{\partial \tau_{1}}=\lambda^{0} \frac{-\frac{\partial q}{\partial \tau_{1}}\left[\lambda^{0}(1-q)+\lambda^{1} q\right]-(1-q)\left[-\lambda^{0} \frac{\partial q}{\partial \tau_{1}}+\lambda^{1} \frac{\partial q}{\partial \tau_{1}}\right]}{\left[\lambda^{0}(1-q)+\lambda^{1} q\right]^{2}}=\frac{-\lambda^{0} \lambda^{1} \frac{\partial q}{\partial \tau_{1}}}{\left[\lambda^{0}(1-q)+\lambda^{1} q\right]^{2}}<0
$$

In words, an increase in the level of court error $\tau_{1}$ reduces the probability that the potential defendant chooses to be no-grossly-negligent, and hence, reduces the general level of care, and increases the unconditional probability of an accident, $\mu=\lambda^{0}+p\left(\lambda^{1}-\lambda^{0}\right)$.

Given that $\frac{\partial q}{\partial \tau_{1}}>0$, then, the effect of $\tau_{1}$ on the conditional probability of trial can be obtained as follows.

Differentiating the conditional probability of trial, equation (8), with respect to $\tau_{1}$ yields

$$
\begin{aligned}
& f A \frac{\left[-\frac{\partial q}{\partial \tau_{1}}\left(1-\tau_{1}-\tau_{2}\right)-(1-q)\right]\left[\left(1-\tau_{1}\right) A+K_{D}\right]+A(1-q)\left(1-\tau_{1}-\tau_{2}\right)}{\left[\left(1-\tau_{1}\right) A+K_{D}\right]^{2}}= \\
& =f A \frac{\left\{-\frac{\partial q}{\partial \tau_{1}}\left(1-\tau_{1}-\tau_{2}\right)\left[\left(1-\tau_{1}\right) A+K_{D}\right]-A(1-q) \tau_{2}-(1-q) K_{D}\right\}}{\left[\left(1-\tau_{1}\right) A+K_{D}\right]^{2}}<0 .
\end{aligned}
$$

Hence an increase in $\tau_{1}$ reduces the conditional probability of trial. Q.E.D. 
Proof of Proposition 3.

Differentiating $m$, equation (16), with respect to $\tau_{2}$ yields

$$
\frac{\partial m}{\partial \tau_{2}}=-\frac{c}{\left[\left(1-\tau_{1}\right) f A-K_{P}\right]\left[\lambda^{0}-\lambda^{1} \frac{\tau_{2} A+K_{D}}{\left(1-\tau_{1}\right) A+K_{D}}\right]^{2}}\left[-\lambda^{1} \frac{A}{\left(1-\tau_{1}\right) A+K_{D}}\right]>0 .
$$

Q.E.D.

Proof of Proposition 4 .

The proof proceeds in two parts. First, we show the effects of the introduction of damage caps, and second we prove the effects of the introduction of split-awards.

\section{Part 1.}

Differentiating the probability of filing, equation (16), with respect to $A$ yields

$$
\begin{gathered}
\frac{\partial m}{\partial A}=-\frac{c}{\left[\left(1-\tau_{1}\right) f A-K_{P}\right]^{2}\left[\lambda^{0}-\lambda^{1} \frac{\left(\tau_{2} A+K_{D}\right)}{\left(1-\tau_{1}\right) A+K_{D}}\right]^{2}}\left\{\left(1-\tau_{1}\right) f\left[\lambda^{0}-\lambda^{1} \frac{\tau_{2} A+K_{D}}{\left(1-\tau_{1}\right) A+K_{D}}\right]+\right. \\
\left.+\left[\left(1-\tau_{1}\right) f A-K_{P}\right] \lambda^{1} \frac{\left(1-\tau_{1}-\tau_{2}\right) K_{D}}{\left[\left(1-\tau_{1}\right) A+K_{D}\right]^{2}}\right\}<0
\end{gathered}
$$

Therefore, a reduction in $A$ increases the probability of filing.

Differentiating $q$, equation (18), with respect to $A$ yields

$$
\frac{\partial q}{\partial A}=\frac{\left[\left(F^{-1}(m)\right)^{\prime} \frac{\partial m}{\partial A}-\tau_{2} f\right] f A\left(1-\tau_{1}-\tau_{2}\right)-f\left(1-\tau_{1}-\tau_{2}\right)\left[F^{-1}(m)+K_{P}-\tau_{2} f A\right]}{\left[f A\left(1-\tau_{1}-\tau_{2}\right]^{2}\right.}<0
$$

The last inequality holds because $\frac{\partial m}{\partial A}<0$ and $F^{-1}(m)+K_{P}-\tau_{2} f A>0$.

Given that $\frac{\partial q}{\partial A}<0$, then, the effect of $A$ on the conditional probability of trial and the probability that a defendant chooses to be no-grossly-negligent can be obtained as follows.

Differentiating the conditional probability of trial, equation (8), with respect to $A$ yields

$$
\frac{f(1-q)\left(1-\tau_{1}-\tau_{2}\right) K_{D}+\left[\left(1-\tau_{1}\right) A+K_{D}\right]\left[-f A\left(1-\tau_{1}-\tau_{2}\right) \frac{\partial q}{\partial A}\right]}{\left[\left(1-\tau_{1}\right) A+K_{D}\right]^{2}}>0
$$


Hence, the introduction of damage caps, i.e., the reduction in $A$, reduces the conditional probability of trial.

Differentiating the probability that a defendant chooses to be no-grossly-negligent $p$, equation (20), with respect to $A$ yields

$$
\frac{\partial p}{\partial A}=\lambda^{0} \frac{-\frac{\partial q}{\partial A}\left[\lambda^{0}(1-q)+\lambda^{1} q\right]-(1-q)\left(\lambda^{1}-\lambda^{0}\right) \frac{\partial q}{\partial A}}{\left[\lambda^{0}(1-q)+\lambda^{1} q\right]^{2}}=-\frac{\lambda^{0} \lambda^{1} \frac{\partial q}{\partial A}}{\left[\lambda^{0}(1-q)+\lambda^{1} q\right]^{2}}>0 .
$$

In words, an increase in the expected level of court award reduces the probability that the potential defendant chooses to be no-grossly-negligent, and hence, reduces the general level of care, and increases the unconditional probability of an accident, $\mu=\lambda^{0}+p\left(\lambda^{1}-\lambda^{0}\right)$.

\section{Part 2.}

Differentiating the probability of filing, equation (16), with respect to $f$ yields

$$
\frac{\partial m}{\partial f}=-\frac{c\left(1-\tau_{1}\right) A}{\left[\left(1-\tau_{1}\right) f A-K_{P}\right]^{2}\left[\lambda^{0}-\lambda^{1} \frac{\tau_{2} A+K_{D}}{\left(1-\tau_{1}\right) A+K_{D}}\right]}<0 .
$$

Differentiating $q$, equation (18), with respect to $f$ yields

$$
\frac{\partial q}{\partial f}=\frac{\left[\left(F^{-1}(m)\right)^{\prime} \frac{\partial m}{\partial f}-\tau_{2} A\right] f A\left(1-\tau_{1}-\tau_{2}\right)-A\left(1-\tau_{1}-\tau_{2}\right)\left[F^{-1}(m)+K_{P}-\tau_{2} f A\right]}{\left[f A\left(1-\tau_{1}-\tau_{2}\right)\right]^{2}}<0
$$

The last inequality holds trivially because $\left(F^{-1}(m)\right)^{\prime}>0$ and $\frac{\partial m}{\partial f}<0$.

Given that $\frac{\partial q}{\partial f}<0$, then, the effect of $f$ on the conditional probability of trial and the probability that a defendant chooses to be no-grossly-negligent can be obtained as follows.

Differentiating the conditional probability of trial, equation (8), with respect to $f$ yields

$$
\frac{A(1-q)\left(1-\tau_{1}-\tau_{2}\right)-f A\left(1-\tau_{1}-\tau_{2}\right) \frac{\partial q}{\partial f}}{\left(1-\tau_{1}\right) A+K_{D}}>0 .
$$

Differentiating the probability that a defendant chooses to be no-grossly-negligent $p$, equation (20), with respect to $f$ yields

$$
\frac{\partial p}{\partial f}=\lambda^{0} \frac{-\frac{\partial q}{\partial f}\left[\lambda^{0}(1-q)+\lambda^{1} q\right]-(1-q)\left(\lambda^{1}-\lambda^{0}\right) \frac{\partial q}{\partial f}}{\left[\lambda^{0}(1-q)+\lambda^{1} q\right]^{2}}=-\frac{\lambda^{0} \lambda^{1} \frac{\partial q}{\partial f}}{\left[\lambda^{0}(1-q)+\lambda^{1} q\right]^{2}}>0 .
$$

Q.E.D. 
Solution of the Model of Liability and Litigation under the English Rule

\section{Equilibrium Characterization.}

The structure of the equilibrium is similar to the one adopted for the benchmark model. This equilibrium constitutes the unique perfect Bayesian equilibrium of the game that survives Banks and Sobel's (1987) universal divinity refinement under the following conditions:

$$
\begin{gathered}
\left(1-\tau_{1}\right) f A-\tau_{1}\left(K_{P}+K_{D}\right)>\tau_{2}\left(A+K_{P}+K_{D}\right), \\
0 \leq \tau_{1}<\min \left\{\hat{\tau_{1}}, \frac{f A-F^{-1}(\bar{m})}{f A+K_{P}+K_{D}}\right\} \\
0 \leq \tau_{2}<\min \left\{\hat{\bar{\tau}_{2}}\left(\tau_{1}\right), \frac{K_{P}+K_{D}}{f A+K_{P}+K_{D}}\right\}
\end{gathered}
$$

where $\hat{m}=\frac{c}{\left[\left(1-\tau_{1}\right) f A-\tau_{1}\left(K_{P}+K_{D}\right)\right]\left[\lambda^{0}-\lambda^{1} \frac{\tau_{2}}{1-\tau_{1}}\right]} \cdot \hat{\overline{\tau_{1}}}$ and $\hat{\overline{\tau_{2}}}\left(\tau_{1}\right)$ correspond to the values for $\tau_{1}$ and $\tau_{2}$ for which $\hat{m}=1.56$

Proposition A1 characterizes the unique universally divine equilibrium of the game under the English rule.

Proposition A1. Assume that conditions (A44)-(A46) hold. Then, the following strategy profile, together with the players' beliefs, represents the equilibrium path of the unique universally divine Perfect Bayesian equilibrium of the game under the English rule.

\section{Strategy Profile}

1) The plaintiff files a lawsuit with probability $\hat{m}=\frac{c}{\left[\left(1-\tau_{1}\right) f A-\tau_{1}\left(K_{P}+K_{D}\right)\right]\left[\lambda^{0}-\lambda^{1} \frac{\tau_{2}}{1-\tau_{1}}\right]}$. In response to an offer $\hat{S}_{1}=0$, the plaintiff rejects the offer (goes to trial) with probability $\hat{\alpha}=\frac{\left(1-\tau_{1}\right) f A-\tau_{1}\left(K_{P}+K_{D}\right)}{\left(1-\tau_{1}\right)\left(A+K_{P}+K_{D}\right)}$ and accepts the offer (drops the action) with probability $(1-\hat{\alpha})$; the plaintiff always accepts the offer $\hat{S}_{2}=\left(1-\tau_{1}\right) f A-\tau_{1}\left(K_{P}+K_{D}\right)$ (settles out-of-court).

\footnotetext{
${ }^{56}$ Conditions (A44)-(A46) are equivalent to conditions (1)-(3) in the benchmark model. Under these conditions, there are other partially separating equilibria and pooling equilibria, which are ruled out by the divinity criterion.
} 
2) The defendant chooses to be no-grossly-negligent with probability

$\hat{p}=\frac{\left[\frac{\left(1-\tau_{1}\right) f A-F^{-1}(m)-\tau_{1}\left(K_{P}+K_{D}\right)}{\left(f A+K_{P}+K_{D}\right)\left(1-\tau_{1}-\tau_{2}\right)}\right] \lambda^{0}}{\left[\frac{\left(1-\tau_{1}\right) f A-F^{-1}(m)-\tau_{1}\left(K_{P}+K_{D}\right)}{\left(f A+K_{P}+K_{D}\right)\left(1-\tau_{1}-\tau_{2}\right)}\right] \lambda^{0}+\left[\frac{F^{-1}(\hat{m})+\left(1-\tau_{2}\right)\left(K_{P}+K_{D}\right)-\tau_{2} f A}{\left(f A+K_{P}+K_{D}\right)\left(1-\tau_{1}-\tau_{2}\right)}\right] \lambda^{1}}$. The grossly negligent defendant makes no offer (offers $\hat{S}_{1}=0$ ) with probability $\hat{\beta}=\frac{\left[\left(1-\tau_{2}\right)\left(K_{P}+K_{D}\right)-\tau_{2} f A\right)(1-q)}{q\left[\left(1-\tau_{1}\right) f A-\tau_{1}\left(K_{P}+K_{D}\right)\right]}$ and offers $\hat{S}_{2}=$ $\left(1-\tau_{1}\right) f A-\tau_{1}\left(K_{P}+K_{D}\right)$ with probability $(1-\hat{\beta})$. The no-grossly-negligent defendant always makes no offer (offers $\hat{S}_{1}=0$ ).

Plaintiff's Beliefs

The equilibrium beliefs are as follows. If an accident occurs, the plaintiff believes with probability $(1-\hat{q})$ that she is confronting a no-grossly-negligent defendant, and with probability $\hat{q}$ that she is confronting a grossly negligent defendant. When the plaintiff receives an offer, she updates her beliefs using Bayes' rule: when she receives an offer $\hat{S}_{1}=0$, she believes with probability $\frac{(1-\hat{q})}{\hat{q} \hat{\beta}+(1-\hat{q})}$ that she is confronting a no-grossly-negligent defendant and with probability $\frac{\hat{q} \hat{\beta}}{\hat{q} \hat{\beta}+(1-\hat{q})}$ that she is confronting a grossly negligent defendant; when the plaintiff receives an offer $\hat{S}_{2}=$ $\left(1-\tau_{1}\right) f A-\tau_{1}\left(K_{P}+K_{D}\right)$, she believes with certainty that she is confronting a grossly negligent defendant. The off-equilibrium beliefs are as follows. When the plaintiff receives an offer $S^{\prime}$ such that $0<S^{\prime}<\left(1-\tau_{1}\right) f A-\tau_{1}\left(K_{P}+K_{D}\right)$ or when she receives an offer $S^{\prime}>\left(1-\tau_{1}\right) f A-\tau_{1}\left(K_{P}+K_{D}\right)$, she believes that this offer was made by a grossly negligent defendant.

Proof.

Following the steps described in the proof of Proposition 1, it is easy to show that Proposition 5 holds. Q.E.D.

\section{Equilibrium Solution.}

The model is solved backwards. We start by finding the solution of the pre-trial bargaining subgame. Then, we evaluate the plaintiff's filing decision and assess the defendant's choice of care.

Note first that under the English rule, the expected payoff at trial for the no-grossly-negligent and grossly negligent defendants are $-\tau_{2}\left(A+K_{P}+K_{D}\right)$ and $-\left(1-\tau_{1}\right)\left(A+K_{P}+K_{D}\right)$, respectively. The expected payoff at trial of the plaintiff is $\tau_{2} f A-\left(1-\tau_{2}\right)\left(K_{P}+K_{D}\right)$ if the defendant is nogrossly-negligent, and it is equal to $\left(1-\tau_{1}\right) f A-\tau_{1}\left(K_{P}+K_{D}\right)$ if the defendant is grossly negligent. 
The values of $\hat{\alpha}$ and $\hat{\beta}$ are calculated from the condition that both parties (the plaintiff and the grossly negligent defendant) have to be indifferent between their strategies to mix them. ${ }^{57}$ Then,

$$
\hat{\alpha}=\frac{\left(1-\tau_{1}\right) f A-\tau_{1}\left(K_{P}+K_{D}\right)}{\left(1-\tau_{1}\right)\left(A+K_{P}+K_{D}\right)}
$$

and

$$
\hat{\beta}=\frac{\left[\left(1-\tau_{2}\right)\left(K_{P}+K_{D}\right)-\tau_{2} f A\right)(1-q)}{q\left[\left(1-\tau_{1}\right) f A-\tau_{1}\left(K_{P}+K_{D}\right)\right]} .
$$

The expected litigation payoffs for the plaintiff and no-grossly-negligent and grossly negligent defendant are $V_{P}=\hat{q}(1-\hat{\beta})\left[\left(1-\tau_{1}\right) f A-\tau_{1}\left(K_{P}+K_{D}\right)\right]=\hat{q} f A\left(1-\tau_{1}-\tau_{2}\right)+\tau_{2} f A-[(1-\hat{q})(1-$ $\left.\left.\left.\tau_{2}\right)+\hat{q} \tau_{1}\right]\left(K_{P}+K_{D}\right), V_{D^{1}}=-\left[\hat{q}\left(1-\tau_{1}\right)+(1-q) \tau_{2}\right)\right] f A-\left[\hat{q} \tau_{1}+(1-\hat{q})\left(1-\tau_{2}\right)\right]\left(K_{P}+K_{D}\right)$ and $V_{D^{0}}=-\left[\left(1-\tau_{1}\right) f A-\tau_{1}\left(K_{P}+K_{D}\right)\right]$, respectively.

The conditional probability of trial is given by

$$
\hat{\alpha}[1-\hat{q}(1-\hat{\beta})]=\frac{\left(f A+K_{P}+K_{D}\right)(1-q)\left(1-\tau_{1}-\tau_{2}\right)}{\left(1-\tau_{1}\right)\left(A+K_{P}+K_{D}\right)} .
$$

Using the previous results on plaintiff's expected payoff from litigation, we analyze now the plaintiff's decision about filing.

A plaintiff will file a lawsuit if her expected payoff from suing (i.e., expected litigation payoff net of filing costs) is positive, that is if

$$
\hat{q} f A\left(1-\tau_{1}-\tau_{2}\right)+\tau_{2} f A-\left[(1-\hat{q})\left(1-\tau_{2}\right)+\hat{q} \tau_{1}\right]\left(K_{P}+K_{D}\right)-K_{F}>0 .
$$

Then, the probability of filing is

$$
F\left(\left[\hat{q}\left(1-\tau_{1}\right)+\tau_{2}(1-\hat{q})\right] f A-\left[(1-\hat{q})\left(1-\tau_{2}\right)+\hat{q} \tau_{1}\right]\left(K_{P}+K_{D}\right)\right) \equiv m
$$

The defendant is indifferent between taking care and not taking care in equilibrium, and then he randomizes between both strategies. The indifference condition is

$$
c+\hat{m} \lambda^{1} \tau_{2}\left[f A-\frac{\tau_{1}}{1-\tau_{1}}\left(K_{P}+K_{D}\right)\right]=\hat{m} \lambda^{0}\left[\left(1-\tau_{1}\right) f A-\tau_{1}\left(K_{P}+K_{D}\right)\right] .
$$

\footnotetext{
${ }^{57}$ These conditions are as follows: $\left(1-\tau_{1}\right) f A-\tau_{1}\left(K_{P}+K_{D}\right)=\hat{\alpha}\left[\left(1-\tau_{1}\right)\left(A+K_{P}+K_{D}\right)\right]+(1-\hat{\alpha})(0)$, and $0=\frac{\hat{q} \hat{\beta}}{\hat{q} \hat{\beta}+(1-\hat{q})}\left[\left(\left(1-\tau_{1}\right) f A-\tau_{1}\left(K_{P}+K_{D}\right)\right]+\frac{1-\hat{q}}{\hat{q} \hat{\beta}+(1-\hat{q})}\left[\left(\tau_{2} f A\left(1-\tau_{2}\right)\left(K_{P}+K_{D}\right)\right]\right.\right.$, for the grossly negligent defendant and plaintiff, respectively.
} 
Solving the last equation for $\hat{m}$, we obtain the probability of filing that supports the randomization of the choice of care.

$$
\hat{m}=\frac{c}{\left[\left(1-\tau_{1}\right) f A-\tau_{1}\left(K_{P}+K_{D}\right)\right]\left[\lambda^{0}-\lambda^{1} \frac{\tau_{2}}{1-\tau_{1}}\right]} .
$$

It is important to note, that $m>0$ because $\lambda^{0}>\lambda^{1}$ (by assumption) and because condition (A44) ensures that $\frac{\tau_{2}}{1-\tau_{1}}<1$. In addition, conditions (A45) and (A46) guarantee that $m<1$.

Then, using equation (A52), we obtain $\hat{q}$, the probability that an accident is caused by a grossly negligent defendant.

$$
\hat{q}=\frac{F^{-1}(\hat{m})+\left(1-\tau_{2}\right)\left(K_{P}+K_{D}\right)-\tau_{2} f A}{\left(f A+K_{P}+K_{D}\right)\left(1-\tau_{1}-\tau_{2}\right)} .
$$

The expression for $\hat{q}$ is always positive, because $\left(K_{P}+K_{D}\right)>\tau_{2}\left(f A+K_{P}+K_{D}\right)$ by condition (A46). In addition, condition (A45) implies that $\hat{q}<1$.

Then, $\hat{p}$, the probability that a defendant chooses to be no-grossly-negligent is given by

$$
\hat{p}=\frac{\left[\frac{\left(1-\tau_{1}\right) f A-F^{-1}(m)-\tau_{1}\left(K_{P}+K_{D}\right)}{\left(f A+K_{P}+K_{D}\right)\left(1-\tau_{1}-\tau_{2}\right)}\right] \lambda^{0}}{\left[\frac{\left(1-\tau_{1}\right) f A-F^{-1}(m)-\tau_{1}\left(K_{P}+K_{D}\right)}{\left(f A+K_{P}+K_{D}\right)\left(1-\tau_{1}-\tau_{2}\right)}\right] \lambda^{0}+\left[\frac{F^{-1}(\hat{m})+\left(1-\tau_{2}\right)\left(K_{P}+K_{D}\right)-\tau_{2} f A}{\left(f A+K_{P}+K_{D}\right)\left(1-\tau_{1}-\tau_{2}\right)}\right] \lambda^{1}} .
$$

Using the previous results, we now derive the probability of accident $\mu=\lambda^{1} \hat{p}+\lambda^{0}(1-\hat{p})$ and the unconditional probability of trial $\frac{\left(f A+K_{P}+K_{D}\right) \lambda^{1} \hat{p}\left(1-\tau_{1}-\tau_{2}\right)}{\left(1-\tau_{1}\right)\left(A+K_{P}+K_{D}\right)} \hat{m}$, where $\hat{p}$ is given by equation (A55) and $\hat{m}$ is given by equation (A53). 
Proof of Proposition 5.

The proof proceeds in three parts. First, we show that under condition $\left(1-\tau_{1}\right) K_{P}>\tau_{1} K_{D}$, $\left(1-\tau_{1}\right) f A-K_{P}<\left(1-\tau_{1}\right) f A-\tau_{1}\left(K_{P}+K_{D}\right)$. Second, we prove that $\lambda^{0}-\lambda^{1} \frac{\tau_{2} A+K_{D}}{\left(1-\tau_{1}\right) A+K_{D}}<\lambda^{0}-\lambda^{1} \frac{\tau_{2}}{1-\tau_{1}}$. Third, we conclude that under the American rule the probability of filing, $m$ is higher than under the English rule.

Part 1.

By the assumption of Proposition 5,

$$
\left(1-\tau_{1}\right) f A-K_{P}-\left[\left(1-\tau_{1}\right) f A-\tau_{1}\left(K_{P}+K_{D}\right)\right]=\tau_{1} K_{D}-\left(1-\tau_{1}\right) K_{P}<0 .
$$

Part 2.

$$
\begin{gathered}
\lambda^{0}-\lambda^{1} \frac{\tau_{2} A+K_{D}}{\left(1-\tau_{1}\right) A+K_{D}}-\left[\lambda^{0}-\lambda^{1} \frac{\tau_{2}}{1-\tau_{1}}\right]=\lambda^{1}\left[\frac{\tau_{2}}{1-\tau_{1}}-\frac{\tau_{2} A+K_{D}}{\left(1-\tau_{1}\right) A+K_{D}}\right]= \\
=-\lambda^{1} \frac{K_{D}\left(1-\tau_{1}-\tau_{2}\right)}{\left(1-\tau_{1}\right)\left[\left(1-\tau_{1}\right) A+K_{D}\right]}<0 .
\end{gathered}
$$

\section{Part 3.}

In parts 1 and 2 , we show that both terms in the denominator of the expression for $m$ under the American rule are smaller than corresponding terms under the English rule. Hence, $m$, is lower under the English rule. Q.E.D. 
Proof of Proposition 6.

Define

$$
\frac{P_{\text {trial }}^{E R}}{P_{\text {trial }}^{A R}}=\frac{1-\hat{q}}{1-q} \frac{\left(f A+K_{P}+K_{D}\right)\left[\left(1-\tau_{1}\right) A+K_{D}\right)}{\left(1-\tau_{1}\right)\left(A+K_{P}+K_{D}\right) f A} .
$$

The proof proceeds in three parts. First, we show that the second term of equation (A58), $\frac{\left(f A+K_{P}+K_{D}\right)\left[\left(1-\tau_{1}\right) A+K_{D}\right)}{\left(1-\tau_{1}\right)\left(A+K_{P}+K_{D}\right) f A}$, is always greater than unity. Second, we prove that $\hat{q}<q$ if $\tau_{2}>\frac{K_{D}}{K_{P}+K_{D}}$. Finally, we show that under the condition $\tau_{2}>\frac{K_{D}}{K_{P}+K_{D}}$, the term $\frac{1-\hat{q}}{1-q}$ is greater than unity and $\hat{p}>p$, i.e., the level of care is higher under the English rule.

\section{Part 1.}

The term $\frac{\left(f A+K_{P}+K_{D}\right)\left[\left(1-\tau_{1}\right) A+K_{D}\right)}{\left(1-\tau_{1}\right)\left(A+K_{P}+K_{D}\right) f A}$ can be rewritten as

$$
\frac{f A^{2}+A K_{P}+A K_{D}+\frac{f A K_{D}}{1-\tau_{1}}+\frac{K_{P} K_{D}}{1-\tau_{1}}+\frac{K_{D}^{2}}{1-\tau_{1}}}{f A^{2}+f A K_{P}+f A K_{D}}>1
$$

because $A K_{P}>f A K_{P}$ and $A K_{D}>f A K_{D}$.

\section{Part 2.}

$\hat{q}<q$ if and only if

$$
\frac{F^{-1}(\hat{m})+\left(K_{P}+K_{D}\right)\left(1-\tau_{2}\right)-f A \tau_{2}}{f A+K_{P}+K_{D}}<\frac{F^{-1}(m)+K+P-\tau_{2} f A}{f A} .
$$

Given that $f A+K_{P}+K_{D}>f A$ and $\hat{m}<m$ (filing is lower under the English rule), $\left(K_{P}+\right.$ $\left.K_{D}\right)\left(1-\tau_{2}\right)<K_{P}$ is a sufficient condition for $\hat{q}<q$ to hold. It is straightforward to show that $\left(K_{P}+K_{D}\right)\left(1-\tau_{2}\right)<K_{P}$ is equivalent to $\tau_{2}>\frac{K_{D}}{K_{P}+K_{D}}$.

\section{Part 3.}

$\frac{1-\hat{q}}{1-q}>1$ if and only if $\hat{q}<q$. Hence, $\frac{1-\hat{q}}{1-q}>1$ holds if $\tau_{2}>\frac{K_{D}}{K_{P}+K_{D}}$. Therefore, under this condition $\frac{P_{\text {trial }}^{E R}}{P_{\text {trial }}^{A R}}>1$. Furthermore, $\hat{q}<q$ implies $\hat{p}>p$. In words, a switch to the English rule raises the level of care, and hence reduces the unconditional probability of accident.

Q.E.D. 


\section{References}

Babcock, L. and Pogarsky, G. "Damage Caps and Settlement: A Behavioral Approach." Journal of Legal Studies, Vol. 28 (1999), pp. 341-370.

Banks, J.S. and Sobel, J. "Equilibrium Selection in Signaling Games." Econometrica, Vol. 55 (1987), pp. 647-661.

Bernardo, A.E., Talley, E. and Welch, I. "A Theory of Legal Presumptions. Journal of Law, Economics, and Organization, Vol. 16 (2000), pp. 1-49.

Economic Report of the President. United States Government Printing Office, Washington, pp. 203-221, 2004.

Cooter, R. and Ulen, T. Law and Economics. Pearson Addison Wesley, New York, 2004.

Daughety, A. and Reinganum, J. "Found Money? Split-Award Statutes and Settlement of Punitive Damages Cases." American Law and Economics Review, Vol. 5 (2003), pp. 134-394.

Dodson, S. "Assessing the Practicality and Constitutionality of Alaska's Split-Recovery Punitive Damages Statute." Duke Law Journal, Vol. 49 (2000), pp. 1335-1369.

Epstein, K. "Punitive Damage Reform: Allocating a Portion of the Award to the State." The Review of Litigation, Vol. 13 (1994), pp. 597-621.

Hughes, J. and Snyder, E. "Litigation and Settlement under the English and American Rules: Theory and Evidence." Journal of Law and Economics, Vol. 38 (1995), pp. 225-250.

Hylton, K. "An Asymmetric-Information Model of Litigation." International Review of Law and Economics, Vol. 22 (2002), pp. 153-175.

Hylton, K. "Litigation Cost Allocation Rules and Compliance with the Negligence Standard." Journal of Legal Studies, Vol. 22 (1993), pp. 457-476.

Kahan, M. and Tuckman, B. "Special Levies on Punitive Damages: Decoupling, Agency Problems and Litigation Expenditures." International Review of Law and Economics, Vol. 15 (1995), pp. $175-85$.

Landeo, C.M., Nikitin, M., and Babcock, L. "Split-Awards and Disputes: An Experimental Study of a Strategic Model of Litigation." Journal of Economic Behavior and Organization, forthcoming

Landeo, C.M. and Nikitin, M. "Split-Award Tort Reform, Firm's Level of Care and Litigation Outcomes." Mimeo, University of Alberta, Department of Economics, 2006. http://www.arts.ualberta.ca/ econweb/landeo/.

O'Connell, J. "Blending Reform of Tort Liability and Health Insurance: A Necessary Mix." Cornell Law Review, Vol. 79 (1994), pp. 1303-1338.

Png, I.P.L. "Litigation, Liability, and the Incentives for Care." Journal of Public Economics, Vol. 34 (1987), pp. 61-85.

Polinsky, A. "Are Punitive Damages Really Insignificant, Predictable, and Rational? A Comment on Eisenberg et al." Journal of Legal Studies, Vol. 26 (1997), pp. 663-77.

Polinsky, A. and Rubinfeld, D. "Aligning the Interests of Lawyers and Clients." American Law and Economics Review, Vol. 5 (2003), pp. 165-188. 
Polinsky, A. and Shavell, S. "Legal Error, Litigation, and the Incentives to Obey the Law." Journal of Law, Economics and Organization, Vol. 5 (1989), pp. 99-108.

Reinganum, J. and Wilde, L. "Settlement, Litigation, and the Allocation of Litigation Costs." Rand Journal of Economics, Vol. 17 (1986), pp. 557-566.

Sabry, F. and Dunbar, F. The Propensity to Sue: Why Do People Seek Legal Actions? NERA Economic Consulting, New York, 2004.

Schweizer, U. "Litigation and Settlement under Two-Sided Incomplete Information." Review of Economic Studies, Vol. 56 (1989), pp. 163-178.

Sloane, L. "The Split-Award Statute: A Move Toward Effectuating the True Purpose of Punitive Damages." Valparaiso University Law Review, Vol. 28 (1993), pp. 473-512.

Smith, S., DeFrances, C., Langan, P., and Goersdt, J. "Special Report. Civil Justice Survey of State Courts, 1992. Tort Cases in Large Counties." Bureau of Justice Statistics, United States Department of Justice, NCJ-153177, 1995.

Snyder, E. and Hughes, J. "The English Rule for Allocating Legal Costs: Evidence Confronts Theory." Journal of Law, Economics, and Organization, Vol. 6 (1990), pp. 345-380.

Stevens, C. "Split-Recovery: A Constitutional Answer to the Punitive Damage Dilemma." Pepperdine Law Review, Vol. 21 (1994), pp. 857-908.

Sunstein, C., Kahneman, D., and Schkade, D. "Assessing Punitive Damages (With Notes on Cognition and Valuation in Law)." Yale Law Journal, Vol. 107 (1998), pp. 2071-2153.

Tullock, G. Trials on Trial: The Pure Theory of Legal Procedure. Columbia University Press, New York, 1980.

White, P. "The Practical Effects of Split-Recovery Statutes and their Validity as a Tool of Modern Day 'Tort Reform'." Drake Law Review, Vol. 50 (2002), pp. 593-610. 
FIGURE 1

SEQUENCE OF EVENTS IN THE GAME

Accident does

$D$ chooses level of care $e$ not occur

Game ends

Accident occurs

Nature decides $P$ 's type

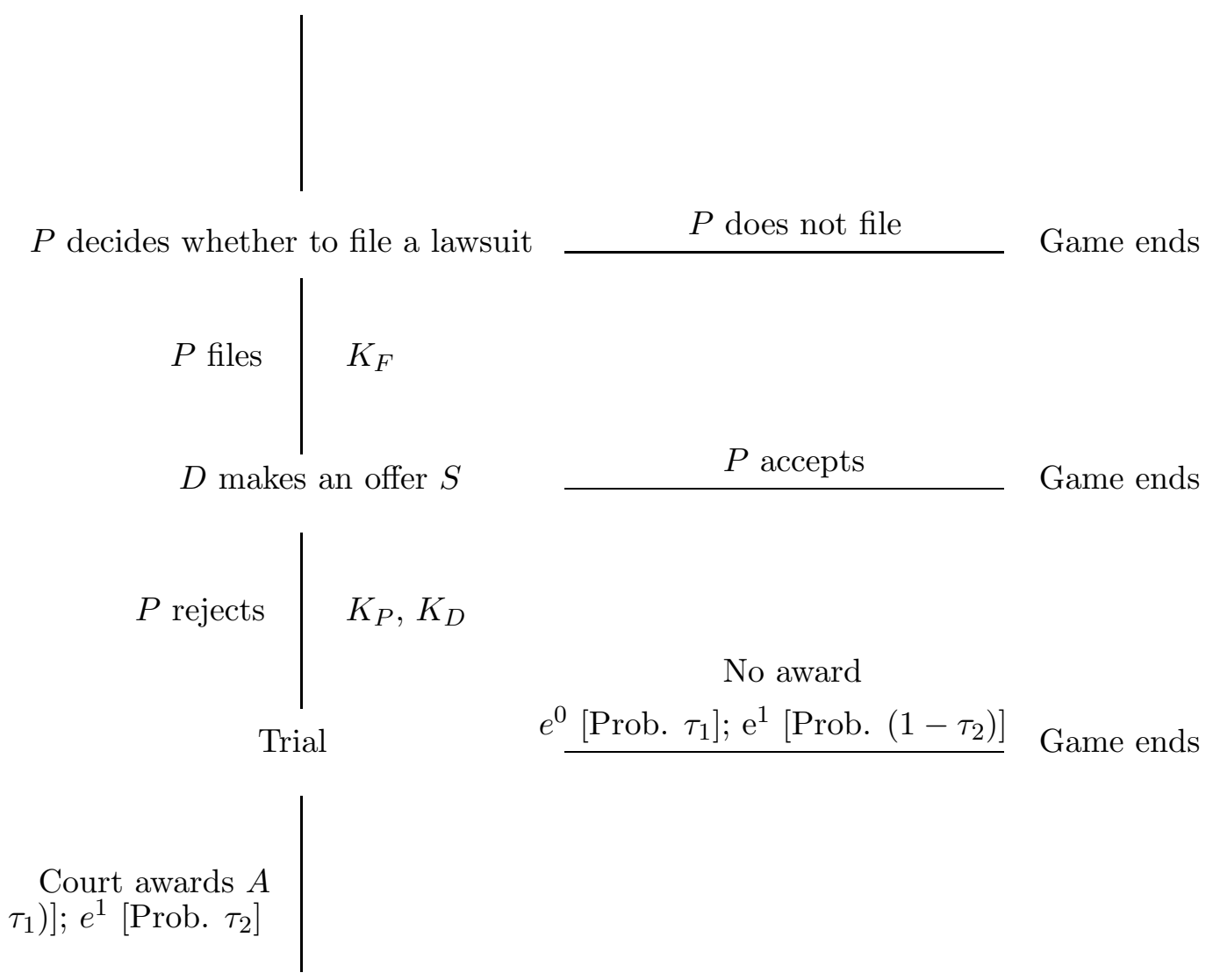

Game ends

Note: $D=$ defendant; $P=$ plaintiff; $K_{F}=$ plaintiff's opportunity cost of time;

$K_{D}=$ defendant's litigation costs; $K_{P}=$ plaintiff's litigation costs;

$A=$ punitive damage award; $e^{0}, e^{1}=$ levels of care; $\tau_{1}, \tau_{2}=$ court's errors. 